University of San Diego

Digital USD

2004-05-01

\title{
Total Resource Sharing among Collegiate and Public Libraries in the Commonwealth of the Northern Mariana Islands: A Narrative Case Study
}

Jimmie L. Ellis EdD

University of San Diego

Follow this and additional works at: https://digital.sandiego.edu/dissertations

Part of the Leadership Studies Commons

\section{Digital USD Citation}

Ellis, Jimmie L. EdD, "Total Resource Sharing among Collegiate and Public Libraries in the Commonwealth of the Northern Mariana Islands: A Narrative Case Study" (2004). Dissertations. 729.

https://digital.sandiego.edu/dissertations/729

This Dissertation: Open Access is brought to you for free and open access by the Theses and Dissertations at Digital USD. It has been accepted for inclusion in Dissertations by an authorized administrator of Digital USD. For more information, please contact digital@sandiego.edu. 
TOTAL RESOURCE SHARING

AMONG COLLEGIATE AND PUBLIC LIBRARIES IN THE COMMONWEALTH OF THE NORTHERN MARIANA ISLANDS:

A NARRATIVE CASE STUDY

\author{
By \\ JIMMIE L. ELLIS \\ A dissertation submitted in partial fulfillment \\ of the requirements for the degree of \\ Doctor of Education \\ University of San Diego
}

May 2004

Dissertation Committee

Robert Donmoyer, Ph.D., Chair Fred McFarlane, Ph.D., Member

Kenneth Galea'i, Ph.D., Member 
(C) Copyright 2004

By

Jimmie L. Ellis

All Rights Reserved

Reproduced with permission of the copyright owner. Further reproduction prohibited without permission. 


\begin{abstract}
Especially in difficult economic times, educational and public sector organizations are under pressure to do more with less. At times, this means consolidating organizations to avoid costly duplication. This study focused on three attempts at consolidation that occurred on the island of Saipan and the two major outer islands of the Commonwealth of the Northern Mariana Islands (CNMI). These efforts entailed total resource sharing across the collegiate and public libraries on these islands.
\end{abstract}

Total resource sharing among the collegiate and public libraries in the CNMI was first envisioned in the late 1980 s and early 1990 s. By 1994, the concept of total resource sharing was beginning to be implemented on the two outer islands; today the concept is fully operational in all three island locations. This research studied ex post facto the strategies that those who developed and promoted the total resource sharing idea used to get the idea implemented in the three settings. Qualitative interviewing and document analysis were the primary research methods employed in the study.

The study identified and the dissertation documents indigenous cultural factors-factors referred to within the CNMI as "the Chamorro way"--that needed to be taken into account by those who led the approval and implementation effort. These factors include cultural norms and rules about who gets to take credit for an idea, what women can and cannot do, and the appropriate role for an outsider or a non-Chamorro. 
The study also documents how the very different political contexts on the mayordominated outer islands, on the one hand, and the more politically-complex island of Saipan where power is more diffuse, on the other, required those who led the resource sharing initiative to propose very different methods for accomplishing resource sharing in each environment. Finally, the study documents how leaders of the process effectively exploited economic crises in some cases to "sell" the resource sharing concept.

This study will add to a small, but growing, literature describing resource sharing among public and academic libraries. The strategies and thinking that leaders used should also be adaptable to other policy arenas. 


\section{Dedication}

I would like to take the time to dedicate this work to my sweet wife, Julie. Without her love and support, this dissertation would never have been completed. I also want to dedicate it to my six children, Travis, Aaron, Heather, Michael, Lindsay, and Megan. You have all been my inspiration in life. I hope that I am an inspiration to all of you. 


\section{Acknowledgments}

First of all, I would like to publicly thank my Heavenly Father for His inspiration when I needed it most, and for His continual uplifting of my spirit whenever it was needed.

I would now like to take time to acknowledge many special people that mentored, inspired, assisted, and drove me to complete the degree program and this dissertation.

Dr. Bob Donmoyer. My thanks to you for the many long hours you spent teaching, me, discussing not only the dissertation, but life, with me, and commenting on/making suggestions to improve my writing and my work. You have been a great mentor and I appreciate all you have done. Thank you most of all for your friendship and caring manner.

Dr. Fred McFarlane. Without your hard work and dedication this Pacific Cohort would never have come to pass. Your dedication to the people of Micronesia will go on in the legacy you created by those of us you encouraged to enter this program. It has been an inspiration for the people of Micronesia to see many of their own accomplish this highly respected degree. I also thank you for the occasional "kick in the pants" to finish my dissertation. Thank you for you also for your warmth and friendship.

Dr. Ken Galea'i. To my Samoan "brother" who is always a source of inspiration and strength. I thank you for accepting me as a fellow islander. Although my birth precludes me being a native Pacific islander, the friendship, hospitality, and caring shown me by yourself and many others from the Pacific have made me an "island boy." I learned more about sharing, caring, and being a Christian from you and your fellow islanders than I ever did in any church. Thank you, my friend. 
Ms. Beth Yemma: Beth, thank you for all the emails and letters you sent to Saipan keeping me up to date on what was needed or due throughout this program of study. Your assistance saved me countless hours of frustration on many occasions. Your help insuring all the paperwork was completed and correct so I could finally have my dissertation defense removed a lot of stress and helped me concentrate on my work.

Ms. Agnes Manglona McPhetres. President Emerita of Northern Marianas College. You will always be "my President." I cannot thank you enough for your leadership and vision while you served as President of the College. You were the finest boss that I ever had the opportunity to work for. I thank you for your vision on the total resource sharing plan among the libraries of the C.N.M.I. and for the role I was assigned in helping to institute that vision. President, you are truly one of the great ladies of the Pacific. I consider you a dear friend and look forward to my next visit to Saipan and your unmatched hospitality. Si Yuus Ma'ase! 
TABLE OF CONTENTS . $\mathrm{x}$

\section{CHAPTER}

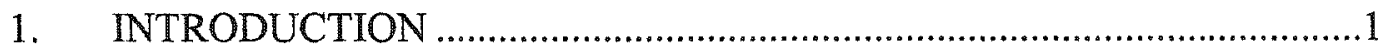

Background to the Study ........................................................

Statement of the Problem ................................................................

Purpose of the Study ............................................................

Research Questions......................................................................

Methodological Approach ..........................................................

Significance of the Study ............................................................. 3

Definition of Terms...................................................................4

Organization of the Dissertation ...............................................5

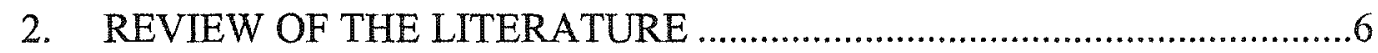

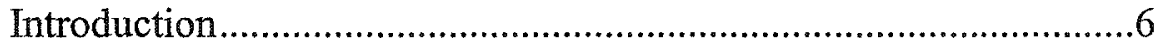

Eliminating Government Duplication of Services ......................... 7

Business Process Reengineering ...............................................8

Definition and Characteristics of BPR ............................. 8

A Brief Historical Account of Business Practices ................9

Using the Above History to Make Sense

of the Context for this Study ...............................................11

Required Preconditions to Make BPR Work .......................13

Relating the Preconditions Analysis to the Research

Context...........................................................................14

Positive and Some Not-So-Positive Views of BPR ...............14

Organizational Change: Problems in Merging Organizational

Cultures ........................................................................................ 15

An Overview of Public Library, School Library, and Academic Library Cooperation from the Late 1800s Until the 1990s...............17

Modern Attempts at Resource Sharing, Cooperation, and

Consolidation...

A Brief Pre-History, Geographic, Political, and Cultural History Of Micronesia and the Commonwealth of the Northern Mariana

Islands

Library Cooperation and Resource Sharing in Micronesia and Specifically in the Commonwealth of the Northern Mariana

Islands

Conclusion

3. METHODOLOGY ….....................................................................4 44

Characterization of the Research Methodology ..............................44 
Description of Specific Research Procedures ..................................46

Site Selection ..................................................................46

Access ..............................................................................4

Researcher Role ............................................................48

Data Collection Procedures................................................49

The Interviewees ..................................................50

The General Interview Strategies Employed .............50

Three Additional Data Collection Procedural

Factors..................................................................52

Additional Data Employed .....................................54

Informally Gathered Participant Observation

Data..................................................................55

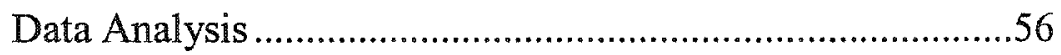

Limitations to the Study ..........................................................5

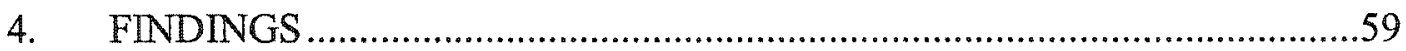

The Cultural Context....................................................................59

Male Dominance of the Culture.........................................60

The Norm of Secrecy with Information..............................61

An Oral Tradition...........................................................62

The Norms of "Saving Face" and Respecting Elders ............62

The Economic Context ..............................................................63

The Political Context ....................................................................64

Library Resource Sharing on Saipan and the Outer Islands:

A Chronology of Significant Events.............................................67

The Genesis of the Resource Sharing/Consolidation

Idea .........................................................................67

Alternative Versions of the Genesis Storyline......................69

One Constant in all of the Outer Island Storylines:

The Outer Island Mayors' Power.........................................72

How the Mayors' Power Impacted the Library Resource

Sharing Story ................................................................... 74

Wielding the Weapon of Accreditation ...............................75

Fortuitous Circumstance: The Case of Rota ........................76

A Different Set of Fortitutious Circumstances: The Case of

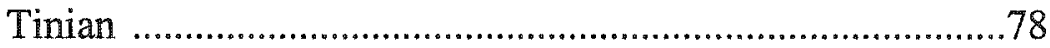

Two Happy Endings for the Outer Islands Library

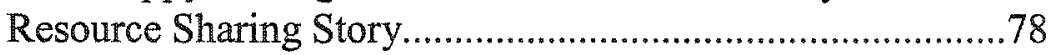

Meanwhile Back on Saipan ..............................................79

It's all in the Timing (and the Right Personnel) ...................79

Creating a Consortium on Saipan .......................................81

Why Form a Consortium Rather than Consolidate................84

Conclusion: Postscripts to the Consolidation/Consortium

Storylines 


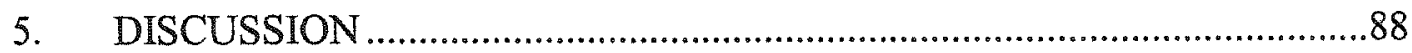

A Review of Key Findings Organized Around the Three

Research Questions: The Importance of Context in Understanding Leadership Challenges, Strategies, and Styles

Question \#1: What Were the Major Challenges

Encountered in Achieving Total Resource Sharing

Among Public and Collegiate Libraries in the

Commonwealth of the Northern Mariana Islands .88

The Challenge of Exploiting an Economic Crisis.................89

The Challenge of Understanding the Cultural Context..........91

The Importance of Understanding and Adapting to the Political Context

Question \#2: How Were the Leadership Challenges Addressed;

Were They Solved, and, if so, How Were They Solved

Question \#3: What Type(s) of Leadership Emerged in

Response to These Challenges......................................................95

Implications for Policy and Practice ..............................................96

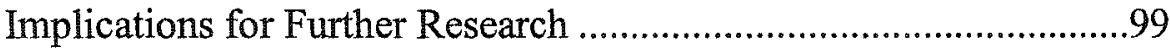

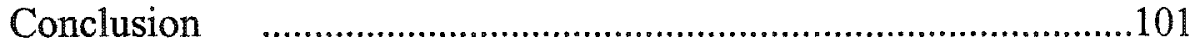

REFERENCES

APPENDIX

A. Maps of the Pacific Islands and the Commonwealth of the

Northern Mariana Islands

B. Time Lines for the Consolidation Process on Rota and Tinian

and the Cooperation Process on Saipan

C. Sample Consent Form

D. Sample of the Interview Questions 


\section{CHAPTER ONE}

\section{INTRODUCTION}

\section{Background to the Study}

In this era of reduced funding, increased competition for existing funds, and increasing accountability, efficiency and cooperation within and between government agencies is crucial. The need to avoid needless duplication of resources becomes especially important during times of economic downturn. Osborne and Gaebler (1992) argue that "waste in government is staggering, but we cannot get at it by wading through budgets and cutting line items" (p. 23). Their solution is to "turn bureaucratic institutions into entrepreneurial institutions, ready to kill off obsolete initiatives, willing to do more with less, eager to absorb new ideas" (p. 23).

Unfortunately, eliminating duplication of resources, especially when planning involves inter-agency cooperation, is much easier said than done. There is often great resistance to change. Employees' comfort with old methods and processes, coupled with the apprehension often associated with learning new ways of doing business, can create considerable tension within the workplace. Employees may also be fearful of having to please new and different superiors and uncomfortable with the idea of adjusting to new cultural norms within their organizations. Yet, as Bridges notes, often the changes that are implemented are important to the survival or continued success of an organization: "Change is the name of the game today, and organizations that can't deal with it effectively aren't likely to be around long," (1991, p. ix). Despite the inevitability, and ultimately, the desirability of change, Kanter (1999) cautions, "You have to make sure 
that the goals of people at many levels of the organizations are aligned, and that people get to know each other, before you can expect them to build trust" (p. 2).

Thus, we need to understand the problems that emerge when attempting to initiate change organizations - especially when change requires the formal consolidation of different agencies-so problems can be anticipated and addressed (Kanter, 1999). Such understanding is especially important in the case of libraries because the high costs associated with the technology explosion make initiatives to eliminate duplication and foster shared relations virtually inevitable (Anderson, 1997).

Statement of the Problem

Typically, in the United States and its possessions, public and collegiate libraries exist as separate entities with little or no sharing of resources other than some interlibrary loan of materials and/or shared union lists of holdings. In these financially stressed times it makes sense to explore the possibility of dropping the old paradigm of having separate, comprehensive resources in both collegiate and public libraries, and, when possible, replace it with a new paradigm of shared resources. We need to know what challenges arise when doing this; how these challenges get resolved; and the role, function, and nature of leadership in resolving difficulties that arise in attempts to share resources across collegiate and public libraries.

Purpose of the Study

The purpose of this study was to document, ex post facto, the challenges and processes involved in planning, creating, and implementing a structure that would facilitate the total resource sharing (including personnel, facilities, budgets, equipment, and materials) among public and collegiate libraries in the Commonwealth of the 
Northern Mariana Islands (C.N.M.I.). The study also took note of economies of scale produced by the resource sharing initiatives.

\section{Research Questions}

The questions guiding the research in this study were:

1. What were the major leadership challenges encountered in achieving total resource sharing among the public and collegiate libraries in the Commonwealth of the Northern Mariana Islands?

2. How were the leadership challenges addressed; were they solved; and if so, how were they solved?

3. What type(s) of leadership emerged in response to these challenges?

\section{Methodological Approach}

This study is a case study involving two organizations located at three separate geographical sites. Since the findings were reported in story form, the study that was done is possibly best characterized as a narrative case study (Polkinghorne, 1995, Yin, 1984, Stake, 1988). Chapter 3 provides a detailed description of how I conducted this narrative case study.

\section{Significance of the Study}

Although some library research has been devoted to the sharing of all resources among academic and public libraries, the preponderance of the research has dealt with interlibrary loan and not across-the-board sharing of resources (i.e., sharing which includes personnel, equipment, funding, facilities, and materials). As continued financial restraints lessen the ability of all libraries to provide basic services, much less extended services, it is imperative that new methods of resource sharing be explored and 
implemented if libraries are to maintain their key role as information providers to their customers. This study added to the small, but growing, literature base on total resource sharing among public and collegiate libraries, particularly in relation to the United States and its extended political family. In addition, I found minimal literature anywhere dealing with any aspects of libraries in the C.N.M.I. Consequently, this study will create a base upon which other studies of libraries in the C.N.M.I. could be built.

\section{Definition of Terms}

To assist the reader throughout this study, terms that need clarification are defined below.

Collegiate libraries: These libraries are located in and maintained by their institution. They constitute libraries serving two-year colleges through the university level.

Chamorro: The indigenous people of the Mariana Islands.

Cooperating library: A library that joins with another library or group of libraries in some common plan, such as coordinated development of collections and services or contribution of entries to a union catalog.

Micronesia: Taken from two Greek words, the term literally means "small islands". These islands lie essentially north of the equator and west of the International Date Line. Northern Mariana Islands: Since 1978, referred to as the Commonwealth of the Northern Mariana Islands, or the CNMI. Geographically, the region includes the island of Guam, however, due to political alignments prior to World War II, Guam became a Territory of the United States while the rest of the Northern Marianas elected to become a Commonwealth of the United States. Of the fourteen islands comprising the C.N.M.I., only three are well populated and of any significance. These three are 
Saipan, (the main island) and the two outer islands of Rota and Tinian. (See map in Appendix A).

Public libraries: These are the libraries that serve the public sector. They are commonly known as "the local library" or the public library.

School libraries: These are libraries located in and maintained by the local school district. They constitute libraries serving grades preK through 12 .

Success: In the context of the process of achieving total resource sharing among public and collegiate libraries in the C.N.M.I., success is used to mean successful implementation of the total resource sharing plan. It does not take into account the views of the customers/patrons on the receiving end of the consolidated libraries' services.

Total resource sharing: This term applies to situations where all resources (including personnel, equipment, funding, facilities, and materials) are shared in some manner. This term is to differentiate from the common use of resource sharing that normally refers to interlibrary loan only.

Union list: A formal list of all the holdings of a particular library. The Organization of the Dissertation This chapter describes the problem that was addressed. Chapter 2 contains a review of relevant literature. The methods used in the study are described in Chapter 3. Chapter 4 presents the findings. Chapter 5 reviews the findings in terms of the three research questions that guided the research and discusses implications for policy and practice, and implications for further research. 


\section{CHAPTER TWO}

\section{REVIEW OF THE LITERATURE}

Introduction

Meyer and Hines (1998) point out the lack of literature on resource sharing in higher education in general when they write: "Resource sharing, as a specific management practice in colleges and universities, is not a widely recognized topic in the literature" (p. 2). Resource sharing between collegiate and public libraries has received almost no attention in the literature. The one notable exception is the rather voluminous interlibrary loan literature.

The dearth of well researched, well documented, scholarly literature on resource sharing between public and academic libraries forced this review of literature to be approached from a rather circumspect route. Consequently, this chapter provides a critical examination of the literature in seven areas.

The first area focuses on literature about current attempts to eliminate duplication in all levels of government. The second area focuses on one current process, business process reengineering, being used in businesses and, increasingly by the government for looking afresh at an organization's products and/or the services it delivers to the customer. The third area provides insight into the problems of organizational change, with specific attention to the concerns of merging organizational cultures and the role of leadership in the change process. The fourth area provides an overview of traditional public library, school library, and academic library cooperation and interaction throughout the $20^{\text {th }}$ century. The fifth area addresses modern attempts at mergers, consolidations, and cooperation among public libraries, school libraries, and academic 
libraries. The sixth area focuses on literature about the history and culture of Micronesia. The final section focuses on library cooperation within the geographical area of Micronesia, and specifically, the Commonwealth of the Northern Mariana Islands.

\section{Eliminating Government Duplication of Services}

Because the vast majority of libraries are supported by taxpayer funds, they are, in effect, governmental institutions. There is a growing recognition among all stakeholders of the need to eliminate duplication of services and waste in all levels of government from the national level through the local level. Often these initiatives are characterized by the label, reinventing government (Osborne and Gaebler, 1992).

The United States Federal Government was last "reinvented during the early decades of the $20^{\text {th }}$ century, roughly during the period 1900 through 1940 . This 'reinventing' of the national government was done to cope with the problems and challenges associated with the emergence of the new industrial economy" (Osborne and Gaebler, 1992, p. xii).

Today we are faced with new challenges brought on by the post-industrial, knowledge-based, global economy. Coupled with this emerging economy are the challenges of the "information explosion" (Ballard, 1990, Rutstein, 1985). As more information demands are required with ever quicker response times, the public requires government to do more with less funding, and to be more accountable for all expenditures. This places libraries in the proverbial position of being "between a rock and a hard place." Obviously, some old paradigms in library methods of operation must be changed to meet the demands of the more diversified library patrons of today. If the gurus of reinventing government are correct, then the traditional library, as we know it, 
may soon be fighting for survival because of the inability to compete with newer, faster sources of information retrieval (Osborne and Gaebler, 1992).

Librarians have traditionally been a staid group, relying on the public at large to have a common sense knowledge of the value of libraries. Assuming the public has this common sense knowledge, librarians use that assumption to justify how they operate. However, in today's advanced technological environment, if librarians are not quick in responding to the rapid technological changes in their field and to customer expectations of rapid response time, they may soon find their organizations fighting for their very survival. If librarians do not begin to adopt some of the practices of the competitive business world, they may soon find themselves no longer needed in today's fast paced, quickly changing world (Anderson, 1997). The next section focuses on one relatively dramatic restructuring approach for any organization, including libraries.

\section{Business Process Reengineering}

Just as government is reinventing itself to eliminate waste through a number of strategies, including organizational consolidation, the business community has also been engaged in a similar process. In the business world, the restructuring process is frequently labeled business process reengineering (BPR).

Definition and Characteristics of $B P R$

Hammer and Champy (1993) define BPR as "the fundamental rethinking and radical redesign of business processes to achieve dramatic improvements in critical, contemporary measures of performance, such as cost, quality, services, and speed" (p. 32). For BPR to succeed, Hammer and Champy (1993) argue, the process must begin with "no assumptions and no givens" (p. 33). Everyone in the organization must first ask 
the two key fundamental questions: "(1) why do we do what we do and (2) why do we do it the way we do it?" (p. 33). A second key to BPR, according to Hammer and Champy (1993) is a commitment to radical (as opposed to incremental) redesign of the organizational structure: "Making superficial changes with what is currently in place is simply not acceptable" (p. 33). The third key to BPR is making dramatic changes or "quantum leaps in performance" (p. 33). Again, small, incremental changes are not indicative of a BPR approach. A Brief Historical Account of Business Practices

Before describing additional features of BPR, it is necessary to provide an overview of past business practices in the United States. This overview is important because it relates directly to where libraries in the C.N.M.I. were in 1994, in relation to their organizational structure, business attitudes, and business practices. This overview will show how American businesses, in general, and the libraries of the C.N.M.I. in particular, had evolved to the point where some type of drastic strategy was needed to insure survival of the organizations.

Most organizations today, no matter what business they are in, can trace their work styles and organizational roots back to the type of factory that Adam Smith described in The Wealth of Nations, published in 1776 (Hammer and Champy, 1993). The cornerstone of Smith's principles was what he called the principle of division of labor.

The population of the U.S. exploded from 1776 to 1825 , creating a huge, new national market. In addition to this national market, an innovative method of transportation was instituted. America began to construct railroads and "the railroad 
companies invented the modern business bureaucracy" (Hammer and Champy, 1993, p. 13).

The next evolutionary step in the development of today's business organizations came early in the $20^{\text {th }}$ century. Henry Ford inaugurated the assembly line into his automobile plants. "Ford succeeded in making jobs infinitely more simple, yet he made the process of coordinating the people performing those jobs far more complex" (Hammer and Champy, 1993, p. 14). Then, Alfred Sloan, CEO for General Motors, created the prototype of the management system that Ford's more efficient factory system demanded (Hammer and Champy, 1993).

Sloan applied Adam Smith's principle of the division of labor to management, just as Ford had applied it to production. Corporate executives no longer needed expertise in engineering or manufacturing; specialists could oversee these jobs while top management needed only financial expertise (Hammer and Champy, 1993, pp. 14-15).

Organizations finally evolved into what we know them today. Top executives at Ford, ITT, and GE created "elaborate planning exercises where senior managers determined the businesses they wanted to be in, how much capital they should allocate to each business and what returns they would expect" (Hammer and Champy, 1993, p. 15). These same authors go on to state that:

This process was exported worldwide and was sustainable until the number of tasks grew to such proportion that the overall processes of producing a product or delivering a service became extremely difficult. The price paid for this phenomenal expansion became a huge middle management, the increasing distance that separated top management from the customer, and ultimately, customer dissatisfaction (Hammer and Champy, 1993, p. 16).

Hammer and Champy (1993) breakdown organizations into three categories in relation to the need for BPR: 
1) organizations that are in deep trouble financially and must take quick, drastic changes to survive, 2) organizations not yet in trouble, but whose management has the foresight to see trouble on the horizon, and 3) organizations that are healthy but want to leave the competition far behind (p. 34).

Using the Above History to Make Sense of the Context for this Study

By late 1994, the libraries in the C.N.M.I. were in category two of Hammer and Champy's identification of organizations needing to implement BPR. The condition of the libraries in the CNMI in 1994 was as follows: The Commonwealth Public Library had two neglected branch libraries on the islands of Rota and Tinian. These facilities were understaffed, under-budgeted, and had holdings that were outdated and mostly useless to the citizens of their respective islands. Neither branch library had computers and, consequently, could not be connected to the Internet. What staff there was in the branch libraries were political appointees with little, or no, professional training in library functions. The main Public Library on Saipan was following outdated business practices of a large middle management, specialists for every library task, increased distance of the Commonwealth Director of the Public Library from the patrons (customers), and as a result of these outdated practices, growing customer dissatisfaction. This scenario often applies to libraries in general (Anderson, 1997).

The collegiate libraries at the satellite campuses for Northern Marianas College (NMC), located on Rota and Tinian, were not in significantly better condition than the Public Library branches on these same islands of Rota and Tinian. The Borja Memorial Library (main library for the NMC) was duplicating the situation at the main Public Library with a large middle management, increased distance of the Director of Library Services from the patrons (customers), and growing customer dissatisfaction. Coupled with the overall state of affairs in the public and collegiate libraries in the C.N.M.I. was 
the dip in the C.N.M.I. economy due to the Persian Gulf War. Because of the war, many Asians, especially the Japanese, dropped vacation plans to visit the C.N.M.I. for fear of attacks by middle-East terrorists. The combination of the overall state of the public and college libraries on Rota and Tinian, coupled with the reduced financial resources available for a period of time to all C.N.M.I. government agencies due to reduced revenues from tourism, presented a blueprint for disaster in the near future if someone in a leadership role did not step forward and address the situation quickly, drastically, and effectively. This proactive stance, in fact, led to the actions on which this dissertation is focused. As Anderson so aptly expresses it:

In fact, BPR is a polarizing term that has keen adherents and detractors. If libraries can move beyond a reaction to the term, the activities and processes can have a direct relationship to library information services and to the strategic directions of the library (1997, p. 116).

Complementing Anderson's (1997) statement regarding libraries and BPR is Sweeney's (1994) statement that "the post-hierarchical library is a radically redesigned and reengineered concept of a library with an entirely new organizational structure and redesigned work processes" (p. 63). Sweeney (1994) goes on to explain that he coined the term, "post-hierarchical library, to mean a library that will change the nature of library service and library leadership", and "like the electronic library will involve the use of new information technologies, the emerging national information infrastructure (NII), and the electronic highway (National Research Education Network)"' (p. 63).

In conjunction with the radically reengineered library will be roles of the new library leader. "It is critically important for the library leader to be a strategist, communicator, coordinator, planner, motivator, nurturer, recruiter, teacher, negotiator, and mediator," Sweeney (1994, p. 85). Elsewhere he writes, "however, the leaders who 
are successful will not all possess the same personality, but they are likely to share several important traits" (p. 83). The requisite traits of the new library leader are that he or she "must be flexible, energetic, empathetic, wise, creative, courageous, principled, gregarious, determined, and possessed of a sense of humor" (p. 83).

\section{Required Preconditions to Make BPR Work}

Before expounding further on BPR, the literature review will first address some preconditions within an organization that must be looked to before BPR implementation. These preconditions had a direct relationship to the libraries in the C.N.M.I. and justify elaboration.

Perhaps the most important concept, in terms of the success or failure of BPR, is four negative preconditions identified by Bashein \& Markus (1994). These four conditions are: "the presence of consensus decision making at the top level of management; the absence of a sound organization financial condition, a multitude of improvement projects currently underway, and animosity toward information systems and human resources personnel"' (p. 10).

It must be pointed out that Bashein \& Markus (1994) state that consensus decision-making at the top management level is a negative precondition in BPR because decision to implement BPR must be implemented quickly.

A collaborative work style among workers is a positive precondition; however, a culture of consensus decision-making at the top of the organization can delay reengineering efforts and even make completing them impossible. Ironically, a strong leader who is willing to make clear demands on subordinates can be more successful in reengineering than one who allows all major decisions to be made by consensus (Bashein \& Markus, 1994, p. 11). 
Relating the Preconditions Analysis to the Research Context

Fortunately, the four negative preconditions that must be addressed prior to initiating BPR (Bashein \& Markus, 1994) were not present in the C.N.M.I. organizations and leadership involved in the project that was the focus of this research. In fact, this lack of the four negative preconditions was partially responsible for the quick implementation of the C.N.M.I.'s total resource sharing project among its collegiate and public libraries. Positive and Some Not-So-Positive Views of BPR

Hammer and Champy are so convinced of the value of BPR they claim, "the principle of BPR will be as instrumental to post-industrial organizations as was Adam Smith's brilliant discovery of the principle of division of labor" (1993, p. 2). Hammer and Champy go on to emphatically state,

Reengineering isn't another idea imported from Japan. It isn't another quick fix that American managers can apply to their organizations. It isn't a new trick that promises to boost the quality of a company's product or service or shave a percentage off costs. Business Process Reengineering isn't a program to hike worker morale or to motivate the sales force. It won't push an old computer system to work faster. Business Process Reengineering isn't about fixing anything. Business Process Reengineering means starting all over, starting from scratch $(1993$, p. 2).

Before BPR is adopted as the panacea for all organizational ills, however, there is a contrasting voice regarding the value and success of BPR. Although certain major corporations' assessment reports suggest BPR efforts net dramatically positive results, Bashein \& Markus argue that, "consultants, off the record, estimate a 70 percent failure rate overall for BPR projects" (1994, p. 12). If these informed, off-the-record assessments are even somewhat correct, there is clearly reason for concern prior to embarking on the BPR process. Kanter (1999) brings some light to BPR failure when she states, 
Years of study and experience show that the things that sustain change are not bold strokes but long marches - the independent, discretionary, and ongoing efforts of people throughout the organization. Real change requires people to adjust their behavior, and that behavior is often beyond the control of top management (pp. 1-2).

Later, in the same article, Kanter argues "many alliances unravel because, while there is support at the top of the organization, departments at lower levels are left to resolve tensions, answer questions, or fill gaps on their own" (p. 2). Kanter's observations relate directly to two of the research questions proposed in this study, namely: (1) what types of challenges were encountered in achieving total resource sharing in the C.N.M.I.? and (2) what type(s) of leadership style arose to meet the challenges that did arise?

The next section of the literature will narrow the focus from an overall business strategy (BPR) to an area of primary importance in the success or failure of consolidation or cooperation.

Organizational Change: Problems in Merging Organizational Cultures

The construct of culture is the central construct used in the discipline of anthropology; it "refers to the relatively enduring set of values and norms that underlie a social system" (Burke \& Litwin, 1992, p. 526). Passed from one generation to the next, a culture is slow to develop and not readily amenable to change. Culture also operates on at least two levels. At the deeper and less visible level, it is constructed around the values shared by a group that persist even when the group's membership changes. If a group culture emphasizes security and predictability over risk-taking and innovation, substituting new values for old may be a major effort (Kotter\& Heskett, 1992).

It was this very concept of merging the sometimes very different organizational cultures of the collegiate and public libraries in the C.N.M.I. that concerned some of the 
leaders involved with the consolidation/cooperation process. The literature reviewed in this section suggests that this concern was legitimate because the literature demonstrates that merging distinctly different cultures is never easy.

There are volumes written on organizational change and organizational culture. The literature covers a range of topics. However, scholars are currently focusing on how the differences between organizational cultures affect the outcome of a merger. This process was especially important in the C.N.M.I. libraries' total resource sharing concept.

At a visible level within organizations, culture represents the patterns of behavior that new employees are expected to adopt for doing work. We could term this visible level of culture "work culture". Since employees, and by extension, employers, realize that the elements of "work culture" do exist, then with strong organizational leadership, good organizational communication, and positive personnel attitudes, two or more, work cultures can be molded successfully into a single organizational work culture (Kotter \& Heskett in Shields, 1999, p. 108).

Shields then goes on to elaborate on the one major factor that is responsible for successful organizational change.

The key to successful organizational change is in understanding what behaviors are required to affect the change and then in making the behavioral changes in the way employees work. Therefore, the organization must give attention to the work culture that supports work behaviors. Work culture expresses itself through the behaviors, values, expectations, and attitudes of people who work for the organization. However, work culture develops, maintains itself, and changes as a direct result of an organization's policies, practices, system, structures, and staffing (Shields, 1999, p. 108).

Organizational culture represents the things that employees should be doing in daily organizational life. Work culture has been defined in numerous ways. Most definitions have focused on the beliefs, assumptions, and values that employees share about rules of conduct, leadership styles, administrative procedures, ritual and customs. A strong organizational culture generally results when employees perceive the things they should be doing as positive (Schneider, 1990, Kanter \& Stein, 1992). Conversely, when 
the required behavior, tasks, etc. of a merged organizational culture are not perceived as good, very little that is positive results in the organizational culture of the new organization. However defined, organizational culture is seen as being important in determining an individual's commitment, satisfaction, productivity, and longevity within a group or organization. It remains to be seen if the new organizational culture created by the consolidation and cooperation of collegiate and public libraries in the C.N.M.I. will flourish or create problems within the organization, especially in view of the fact that the speed of the implementation glossed over many of the requirements specified by Kanter (1999) for the successful melding of organizational cultures (see also Bashein \& Markus, 1994). It was of specific interest to find out what types of leadership arose to deal with the challenges of melding the two organizational cultures of collegiate and public libraries in the C.N.M.I.

Now that the importance of organizational culture has been explored it is important to understand, from an historical perspective, the cooperation among public, school, and academic libraries and how libraries in general have arrived at various forms of resource sharing today.

An Overview of Public Library, School Library, and Academic Library Cooperation from the Late 1800s Until the 1990s

Although the cooperative movement between public libraries and school libraries extends back to the late $19^{\text {th }}$ century, these original efforts concentrated on bibliographic descriptions as found in union lists, with no mention of cooperative acquisitions (Rutstein, 1985). 
From late in the $19^{\text {th }}$ century onward there have been many attempts and many approaches to cooperation between and among public, school, and academic libraries (Gerould, 1907, Baldwin, 1922, Bodker \& Anzalone, 1964, Logsdon \& Nelson 1965, Reid, 1965, Brown \& Mashinic, 1983, Schwanz, 2000). In the early part of the 20th century much more funding was available to the public libraries than to school and academic libraries, leading to the school libraries, in particular, to look to the public libraries for assistance (Gerould, 1907, Baldwin, 1922, Reid, 1965, Brown \& Mashinic, 1983).

The main thrust of cooperation from 1900 until the 1940s involved public library support of school curriculums and beginning reader programs (Baldwin, 1922, Pedley, 1946). Later, the Farmington Plan of 1947 , the first major experiment in cooperative collection development, was considered a failure in the long run.

Bach (1957), a librarian, felt that academic libraries of that time were obliged to cooperate at regional and state levels, but that regional agreements would be difficult to draft until libraries better knew their own areas of strength and weakness. The following year, another author (Esterquest, 1958) noted that smaller institutions tended to rely more on larger institutions than on each other for interlibrary loan, placing disproportionate burden on the larger institutions. In 1959, the director of the Stanford libraries reiterated the same theme of burden being placed on larger libraries by smaller libraries, for interlibrary loan. His suggestion was that the resource sharing functions of the larger libraries might profitably be transferred to regional centers such as the Midwest InterLibrary Center (Swank, 1959). This would reduce the burden of interlibrary loan on the 
larger libraries and at the same time spread library resources over a much wider geographical area (Swank, 1959).

Despite such pronouncements of obligation and altruism, the literature suggests that cooperation continued to take a back seat to institutional ego. A study in 1963, found a strong positive correlation between the size of a library and the academic ranking of the institution it served (Piternick, 1963). From that standpoint, the notion of cooperative acquisitions seemed to the larger institutions to be an invitation to academic mediocrity. In addition, the space race funding boom of the 1960s, with its "resultant materials collecting fever in librarians, left individual college and university libraries with neither the desire nor the need for cooperative acquisitions" (Hacken, 1992, p. 18).

In the 1970s the situation began changing again toward a reexamination of cooperation driven by the information explosion, by inflation, by the decrease of budget funds, and by burgeoning automated networks and consortia (Rutstein, 1985). In this new atmosphere, the earlier lessons of the problems associated with unequal partnerships were not forgotten, and the point was made that, "cooperation cannot be based on institutional altruism" (Dougherty, 1975, p. 41). A cooperative system would never thrive with some libraries trying to get something for nothing. Resource sharing could never operate well until goals coincided for all members of the partnership. In addition, "in many instances where cooperation was desired between libraries, there were legal and fiscal barriers to cooperation" (DeGennaro, 1979, p. 327), as well as psychological barriers (Dougherty, 1975).

The tight budgets of the 1980s forced even greater selectivity on libraries, and resource sharing reached new heights-at times transcending the level of planning and 
discussion. In a relative sense, the 1980 s could be called the "Golden Age of Resource Sharing", or at least the most golden so far. The pool of sharable materials, however, did not materialize automatically. In order to be successful, selectors had to follow a careful collection development model (Welsch, 1985) and calculate changing trends in research needs, in financial fluctuation, in the publishing industry, and in automation (Anderson, 1997, Dougherty, 1997).

When libraries acquired the same materials (mirror collected) to a high degree, then cooperative collecting became impossible (Sewell, 1970). It happened that, all too frequently, cooperation was merely a "pooling of poverty" (DeGennaro, 1977), especially when emphasis was put on creating theoretically balanced collections that resembled most other balanced collections. Pooling resources only worked when the pool was expanded (DeGennaro, 1977); otherwise the questionable phenomenon of overlap was overshadowed by the huge problem of collection gaps or "underlap" (Kronick, 1982).

The burden of providing information became so colossal that by the late 1980s the phrase access or ownership (meaning should a library purchase every item it thought it needed or try to form a cooperation with other libraries for access to many items) became the hot topic (Higginbotham \& Bowdoin, 1993, Schwartz, 1997). However, the topic of interlibrary loan is not the focus of this dissertation and will be treated as only one of the many resources to be shared. Additionally, the buzzword phrase of the 1990 s in the library profession was the virtual library (Saunders, 1999, Payne, 1998). The term virtual library, as defined by Saunders, "became a standard way of describing libraries that offer access to digital information using a variety of networks, including the Internet and the World Wide Web" (1999, p. 772). 
The history of library cooperation is relevant to this research because, in addition to the outdated business practices being employed in both the public and collegiate libraries in the CNMI, those same libraries were also duplicating collections, not sharing resources, and competing for the limited funding available from the C.N.M.I. government.

Even more central to the scope of this dissertation is a review of the positive, and to some degree the negative, references to previous attempts at total resource sharing between public, school, and academic libraries since the 1960 s.

Modern Attempts at Resource Sharing, Cooperation, and Consolidation

In 1971, James S. Healey, writing for College and Research Libraries, provided an overview of public and academic library cooperation. Dating back to 1965 , Logsdon \& Nelson laid down some guidelines for effective library cooperation. Their list stated:

1) Cooperation is not good in itself, it is a voluntary act which must be pursued creatively and geared to local situations; 2) Objective appraisal of the results of cooperation is as critical as advance planning and sound implementation; 3 ) Cooperation must take into account the legitimate ambitions as well as the present status of the individual cooperating institution; 4) A precondition to an effective system of interlocking libraries is the creation of an adequate governmental structure to develop and sustain it (p. 122).

The authors were writing of cooperation between academic libraries only, however, these proposed guidelines could also be legitimate for cooperation/consolidation between different types of libraries, for example the public library and school library cooperation, public library and collegiate library cooperation, or a combination of all three. (Healey, 1971).

In a statewide attempt to assess the need for, and the possibility of, resource sharing, John A. Humphry was selected by Brown University to complete a study of the 
entire state of Rhode Island's public school system's library resources. The results of that survey were published in 1963 under the title, Library Cooperation. One of the major recommendations of the report was, "Further cooperation is recommended among the libraries of public and private institutions of higher learning and with public school and public libraries as well" (Healey, 1971, p. 123).

In a related article from 1965, The School-Public Library Crisis, Charles Reid states, "The information and population explosions have combined in this age of change and have converged upon libraries to create a crisis that must be faced and met now" (p. 13). Reid goes on to state, "librarians are apprehensive of what the future portends. They are struggling against almost impossible conditions and historic apathy to cope with the situation" (p. 13). The solution, as Reid sees it, is that something can be done regarding library cooperation if the people operating our democratic institutions, such as schools, colleges, and libraries are willing to sit down and work out solutions to the benefit of our institutions and to the benefit of the communities they serve (1965). It was interesting to note that Reid listed several problem areas for libraries in 1965, which are still problem areas for libraries today. For example, "scientific journals began to be published in 1665 . By 1830 , there were 300 scientific journals, and by 1965 , there were over 100,000 " (1965, p. 13). "Additionally, it has been estimated that the number of book titles published from 1900 - 1950 , equaled the number of books published during the preceding 450 years (Reid, 1965, p. 13). Today, nearly 100,000 books are published per year (C. Bull, September, 2000, personal communication), and the cost for a library to purchase a book has risen from $\$ 5.92$ in 1965 (Reid, 1965) to nearly $\$ 40$ per book today (C. Bull, September, 2000, personal communication). Other problems plaguing 
libraries include: insufficient staff, outdated equipment, insufficient facility space, and insufficient funding (Reid, 1965, C. Bull, September, 2000, personal communication). According to Reid, it is extremely important that each community embark upon a program of total library service by getting all libraries within a community or region into a program of common goals and recognizing their common responsibilities. Public library - school library - academic library cooperation is extremely important to the future strength of our nation because education must be continued throughout our entire lives. "Libraries have the most important role of all in seeing that we, as a society, meet the challenge of education to all of our populace, on all levels" (Reid, 1965, p. 14). The need for library cooperation has been discussed for decades. It has been implementation that has been the problem.

Finally, the literature reveals a success story in library cooperation. In 1983, the Houston Public Library, Houston Independent School District, and Houston Community College began sharing facility space and operating costs at the Carnegie Branch Library and Community Education Center (Brown \& Mashinic, 1983). In this cooperative project, the public schools are contracting with the Houston Public Library for the services; the Community College is leasing the space. It is one of the few times that a cooperative project has been housed in a public library setting (Brown \& Mashinic, 1983). "The multipurpose Carnegie facility is equipped with a photography darkroom, classrooms, meeting space, and audio visual laboratory. The structure also contains a story telling kiosk and puppet theater, complete with marquee lighting" (Brown \& Mashinic, 1983, p. 91). "Benefits of this cooperation include, extended hours of 
operation over regular school library hours, and an expanded collection of books, periodicals, and audio-visual materials" (1983, p. 92).

Another success story comes from Warrensburg, Missouri. In 1980, Ward Edwards Library on the campus of Central Missouri State University (CMSU) and Trails Regional Public Library began negotiations of limited cooperation in preparation for joining the Kansas City Metropolitan Network (Medaris, 1984).

By 1984, the cooperation had evolved from interlibrary loan only, to sharing computer printouts of periodical holdings, sharing listings of newspapers on microfilm, exchange of new book lists, resource sharing by making expensive purchases (such as the Thomas Register) in alternate years, and having staff members from each library serve on common committees, task forces, and the combined library council (Medaris, 1984, p. 67).

The most current cooperation involves allowing checkout privileges to public school teachers and to any citizen with a Warrensburg address (Medaris, 1984).

Dramatically showing the importance of attitude and communication in the success of this joint academic, public library endeavor, Medaris states,

While today we have a comfortable and satisfying relationship with Trails, I hope we are never guilty of "taking them for granted." Their staff is competent and professional, and it is a pleasure to work closely with them; they make cooperation easy" (1984, p. 68).

On a somewhat negative tone regarding public library and school library mergers is the 1991 North Dakota Advisory Council on Libraries article entitled, A Discrete Inquiry: Is the Merging of School and Public Libraries a Viable Option in the State of North Dakota, (NDACL, 1991). A rather interesting portion of this report states:

In anticipation of increased emphasis on library consolidation in the future, a brief analysis of North Dakota's current library situation reveals that it is characterized by inconsistent service, scare funds, and a shortage of options, making merger a possible alternative. This proposal has traditionally been based on the contention that in areas of limited population and resources, the operation of one library is 
more efficient than two, but this theory has not been proven in practice (NDACL, 1991, abstract).

The condition of North Dakota libraries, in the NDACL report of 1991, closely parallels the conditions existing within the libraries in the C.N.M.I. in 1994. The C.N.M.I. libraries were also characterized by inconsistent service (the Public Library had three new Directors in four years), scare funds (due to the Gulf War which directly affected an economic downturn in tourism to the C.N.M.I.), and a shortage of options (neither the public nor collegiate libraries could expand their facilities, collections, or number of personnel).

Although the findings of the NDACL report suggest strongly that merger (or consolidation) is not the most desirable approach, the report does later state, emphatically, "that creative cooperative arrangements are the way for public and school libraries in North Dakota to proceed" (NDACL, 1991, abstract).

However, notice is given by NDACL, "assuming interest, goodwill, and a cooperative mood, it is also extremely important to have details worked out in advance and agreed upon formally" (1991, p. 7). The possibility of exploring more creative arrangements [than consolidation] might begin with coordinating purchases, strengthening interlibrary loan capabilities, and sharing available resources - "all the while maintaining degrees of autonomy, distinct clienteles, and more than likely, separate locations" (NDACL, 1991, p. 8).

Bringing another positive aspect into resource sharing is the current emphasis in the library field on sharing computing resources because economies of scale apply (Morgan, 1998). There are several reasons for this form of resource sharing: 
First, systems-oriented, computer-based networks were seen as an evolutionary next step in library cooperation, and libraries shifted from their participation in less formal cooperative arrangements to membership informal resource-sharing networks. Also, the development of regional networks and bibliographic utilities in the 1970s shifted the emphasis in library cooperation from that of sharing bibliographic information to sharing technology for bibliographic control. The success of these large systems in accomplishing technical processing tasks (such as shared cataloging) which benefit from economies of scale tended to minimize the benefits of interpersonal networking (Ladner, 1992, p. 2).

But in an environment where change is the norm, we always have to be on the lookout for new ways to improve old techniques - techniques for resource sharing and consortium building. Morgan states it this way:

It's the Darwinian way: Only the organisms (read organizations or institutions), which adapt to their environments continue to thrive. Put another way, interlibrary loan is no longer the only resource sharing game in town since our information expectations (like the preponderance of bibliographic databases, Web pages, and document delivery services) have increased in an age of networked computers. Thus we have to think of better ways to network, literally (1998, p. 2).

Even more recent is the planned new library to be built on the campus of San Jose State University, to be co-managed by the Public Library of San Jose (Eberhard, 1999). Although time will tell whether this ambitious consolidation will be a success or not, this new, combined use library would replace the city's Martin Luther King Jr. Public Library and the university's Clark and Walquist Libraries. "Under an operating agreement still awaiting finalization, the university and the city would retain control over their respective collections and budgets, but allow nearly equal access to each other's library materials" (Eberhard, 1999, p. 21).

Another public library and college library cooperation project being proposed is in Seminole, Florida, where the city council voted 6-1 in favor of replacing its community library with a new facility to be shared with students of St. Petersburg Jr. College's new Seminole campus (Eberhard, 1999). Also proposed is the Broward 
County, Florida cooperative library project with Nova Southeastern University, located in Ft. Lauderdale, Florida.

The proposed new five-story, 280,000 square foot library would be used by both Nova students and Broward County residents. Under the proposal, Nova would donate the land and pay $\$ 8$ million towards construction costs and another $\$ 2.5$ million in 10 years for expansion. The county's share would be $\$ 18.7$ million for construction, in addition to assuming the debt risks of building a fee-based parking garage at the site (Eberhard, 1999, p. 22).

The story of library cooperation and library consolidation continues to evolve. To some "it is a hybrid, a hydra to others" (Goldberg, 1996, p. 1). Perhaps Schwartz sums it up best when she proposes, "Whether the result of extensive planning, surveys, and assessments of specific service areas or of something innocuous like an informal brainstorming session by individuals from different institutions, a cooperative venture can be brought into being" (2000, p. 478). As implied in so much of the library literature already noted, communication among, and attitudes of people involved, are the critical foundation for any effective library cooperation efforts. Schwartz synthesis these two foundations into advising any cooperative effort to have a Memorandum of Agreement (MOA) and a timetable (2000). "The MOA should be cooperatively created and deal with the most essential aspects of cooperation, budget management and organization, policies and procedures, and location" (2000, p. 479). The MOA eliminates confusion as to who is to do what, and how, while the timetable enables all participants to realize their joint effort expectations. As Robert Frost once said, "good fences make good neighbors". These words were never truer than on the subject of joint venture libraries (Schwartz, 2000).

In summary, partnerships are far less untidy in the abstract than in real life. What makes this so is the addition of people and their ways of behaving and carrying out tasks. 
People create the environment in which the partnership will thrive - or not (Schwartz, 2000). This merely restates what was so eloquently brought out in the section of this literature review on organizational change and organizational culture, that "you have to make sure that the goals of people at many levels of the organizations [in cooperation or merger] are aligned, and that people get to know each other, before you can expect them to build trust" (Kanter, 1999, p. 2). Duck (1993) supports Kanter's view by adding another dimension regarding people and change. "...change is intensely personal. For change to occur in any organization, each individual must think, feel, or do something different" (p. 109).

To assist people in accepting the merger of two or more organizational cultures becomes the task of the leaders. The question then becomes what do successful leaders do in overcoming the challenges of change that less successful leaders do not do. Goleman (2000), using data derived by the consulting firm of Hay/McBer, postulates there are six distinct leadership styles. Goleman (2000) goes on to use the metaphor of a golf pro selecting various golf clubs (leadership styles) to fit the demands of certain golf shots (the challenges). The six leadership styles derived from Hay/McBer are:

1) coercive leadership, which demands immediate compliance, 2) authorative leadership, which mobilizes people toward a vision, 3) affiliative leadership, which creates emotional bonds and harmony, 4) democratic leadership, which builds consensus through participation, 5) pacesetting leadership, which expects excellence and self direction, and 6) coaching leadership, which develops people for the future (Goleman, 2000, p. 81).

What is important for the leader to understand is that first, no one style works well over the long term unless employed with a second style and second, leaders must "understand how different leadership styles affect performance and results" (Goleman, 2000, p. 82). Because one of the research questions that drove this dissertation has to do with what 
leadership style(s) arose to meet the challenges of total resource sharing among collegiate and public libraries in the C.N.M.I., it was interesting to see the results in the findings and to see if/how they correlated with Goleman's (2000) six leadership styles.

The focus of this review of literature will now deal with libraries in Micronesia, with emphasis on the Commonwealth of the Northern Mariana Islands (C.N.M.I.). However, prior to this focus review, some important background information regarding Micronesia and the C.N.M.I. needs to be presented to assist the reader in better understanding this part of the United States political family.

A Brief Pre-History, Geographic, Political, and Cultural History of and the Commonwealth of the Northern Mariana Islands

Micronesia is the term that has been applied to the 2,106 Pacific islands and atolls that lie essentially north of the equator and west of the International Date Line (Hanlon, 1994). "The term Micronesia was first suggested in 1831 by the French geographer, Domeny de Rienzi, and is derived from a combination of Greek words meaning 'tiny islands"' (R. Hanlon in Howe, Kiste, \& Lal, 1994, p. 1).

The origins of the Micronesian peoples have fascinated and challenged the imaginations of Europeans ever since their first contact. A vast body of literature regarding these peoples has been accumulated, much of it speculative in nature. Despite the absence of written languages among the islanders themselves, their oral histories were, and are, abundant with accounts of far distant homelands, heroic voyages of exploration, and the settlement of new landfalls (R. Hanlon in Howe, et al,. 1994, p. 9).

For a variety of reasons, scientific inquiry as to the early histories of the peoples of Micronesia (and the Pacific as a whole) did not evolve until after WWII. However, since the 1960 's scientific interest, especially among anthropologists has increased dramatically (Howe, et al., 1994). 
Some scholars believe primitive peoples migrating from S.E. Asia had reached the southern Pacific as early as 50,000 years ago (Swadling in Howe, et al., 1994, p. 9).

Kiste reports that,

Somewhere around five thousand years ago, another flow of people out of Southeast Asia began. These migrants were probably ancestors to the Polynesians and Micronesians of today and were speakers of related languages that belong to the Austronesian family of languages. Linguistic evidence suggests that eastern Micronesia was settled by a movement of people northward from eastern Melanesia in the vicinity of Vanuatu. The vast body of archaeological, ethnological, linguistic, botanical, zoological, and other evidence all point to south-east Asian origins for the ancestors of the Pacific Islanders, including the Micronesians (in Howe et al., 1994, p. 9).

It must be noted that the research compiled on the subject of the history of the peoples of the Pacific has been done, mostly, by scholars of non-Pacific Islands descent (Howe, et al., 1994, Hezel \& Berg, 1979, McHenry, 1975, Clyde, 1935). Oral tradition among the islanders, specifically the Samoans, (K. Galea'i, June, 2000, personal communication) and the Chamorros (H. Del Rosario, July, 2000, personal communication) refutes some of what has been quoted from Howe, et al. (1994).

The European period of involvement in Micronesia began with Magellan's landing on Guam in 1521. Magellan's voyage demonstrated the immense size of the Pacific Ocean. During the rest of the $16^{\text {th }}$ century, the Spanish and Portuguese dominated the exploration of this vast Pacific region. Due to the lack of gold or other precious commodities, the islands of Micronesia were left pretty much alone for the next 150 years (Hezel \& Berg, 1979).

The early explorations by Spain in Micronesia "provided the basis for Spanish claims over the Caroline, Mariana, and Marshall Islands" (D. Hanlon in Howe, et al., 1994, p. 94). However, Spain seemed to care little for it claims in Micronesia except for 
Guam and the rest of the Mariana Islands. This lack of concern lasted from early Spanish colonization until the late $19^{\text {th }}$ century when German commercial forays into the area threatened Spanish claims to the territory (D. Hanlon in Howe, et al., 1994).

German take-over of the Marshall and Caroline Islands by a show of navel force created intense reaction in Europe. So outraged were the Spanish, who felt they had legitimate previous claim to these same islands that the Spanish Government contemplated declaring war on Germany. On 17 December 1885, Pope Leo XIII recognized Spanish claims to administer the Carolines, and German rights to trade in the area (Moses \& Kennedy, 1977, Wiens, 1962).

Fortitutious events for Germany finally allowed her to take-over Spanish Micronesia in 1899.

With its defeat at the hands of the United States in the Spanish - American War of 1898, Spain was now forced to relinquish all of its Pacific territories. Secret negotiations between German and Spanish representatives in Paris resulted in the sale of the Mariana and Caroline Islands to Germany (D. Hanlon in Howe, et al. 1994, p. 94).

As with Spain, war would also spell the end of Germany's control over Micronesia. At the outbreak of World War I in Europe, Germany's Pacific possessions were distant, isolated, and indefensible. Beginning in October of 1914, Japan, allied with Great Britain against Germany and the other Axis powers through a 1902 agreement, simply sailed into the various harbors of the Micronesian islands and raised the Japanese flag (Hezel \& Berg, 1979, Peattie, 1988, Howe, et al., 1994). In 1919, the League of Nations formally recognized Japan's occupation of the Micronesian islands through a Class " $\mathrm{C}$ " Mandate. "In effect, the fictitious guardianship on behalf of the League of Nations provided little 
more than a thin cover for the Japanese annexation of Micronesia" (D. Hanlon in Howe, et al., 1994, p. 95).

Guam had come under United States control as a result of the Spanish-American War of 1898, which had marked the United States' formal commitment to imperial expansion in the Pacific. During negotiations over the Treaty of Paris that had defined the terms of peace, American representatives had initially considered the acquisition of the Caroline Islands and later the retention of at least one of the group as a base for maintaining American interests in the area. Ultimately, only Guam was to remain an American possession until after World War II (Quinn, 1945).

At the close of World War II in 1945, the United States had three island territories, all of which had been acquired around the turn of the century. American rule was never challenged in American Samoa and Hawaii during the war, but Guam had fallen to the Japanese immediately after Japan's attack on Pearl Harbor and was not recaptured by the U.S. until 1944. During WWII, America had seized the bulk of Micronesia, including the area administered by Japan as a League of Nations mandated territory between the two world wars. In 1947, Micronesia became the United Nations Trust Territory of the Pacific Islands with formal Class "A" Mandate granted by the U.N. to the United States (R. Kiste in Howe, et al., 1994, p. 227).

This agreement remained in effect until the various entities of Micronesia negotiated varying forms of self-rule. The Marianas (which does not include Guam politically, even though Guam is part of the Marianas geographically) negotiated for, and achieved, Commonwealth status as part of the United States political family in 1978. Today the area remains the Commonwealth of the Northern Mariana Islands (C.N.M.I.) and has local jurisdiction over all aspects of its government except for defense and international affairs.

Geographically, the C.N.M.I. lies on the far eastern edge of Micronesia. Saipan, the capital of the C.N.M.I., lies some 1800 miles south of Tokyo, Japan, and some 1400 
miles east of Manila, Philippines. The C.N.M.I. is comprised of 14 major islands, extending on a north to south axis, and stretching over a distance of approximately 380 miles (Trust Territory Pacific Islands Archives, 1947).

Of the 14 islands, only three, Saipan (population approximately 60,000) Rota, (population approximately 2400), and Tinian, (population approximately 1200), are considered significant due to population, resources, infrastructure, etc. (U.S. Census, 1995, mid-term update). Rota is the southernmost island in the C.N.M.I. and lies 82 miles south of Saipan. Tinian is the third island of the chain (going from south to north) and lies only 3 miles south of Saipan. Only the small, uninhabited island of Aguiguan lies between Rota and Tinian. Saipan is the fourth island in the chain (again going from south to north) and is the site of the C.N.M.I. government (see map, Appendix A, for geographic layout of the C.N.M.I.). Saipan lies 122 statute miles north of Guam (again, Guam is part of the Mariana Islands geographically, however, Guam is not part of the Mariana Islands politically) (Hezel \& Berg, 1979, Howe, et al., 1994). Of the remaining 11 islands in the C.N.M.I., only Anatahan, Alamagan, and Agrigan (all north of Saipan) are populated. The combined population of these three islands is approximately fortyone people, all existing on subsistence farming and fishing (U.S. Census, 1990).

There are modern airports on Saipan, Rota, and Tinian. Currently, only Saipan is served by major airlines with Rota and Tinian served by small feeder airlines using twin engine and single engine aircraft. Airfares range form $\$ 153$ round trip from Saipan to Guam, down to $\$ 50$ round trip from Saipan to Tinian. The only air service to the isolated, sparsely populated northern islands is by helicopter charter, which currently costs approximately $\$ 500$ per flight hour. The nearest inhabited island north of Saipan is 
Anatahan (some 80 air miles away) and approximately two hours flying time for a round trip.

In addition to air transportation, there is regular ferry boat service between Saipan and Tinian. Although Tinian lies only three miles across the channel from Saipan, the Tinian harbor is on the extreme south side of the island thus making the one way trip by ferry approximately 45 minutes. Interesting to note is the ferry service is provided by the Las Vegas type casino and hotel operating on Tinian. If a passenger on the ferry stays overnight at the casino hotel, he or she receives a voucher paying for the round trip. For all other passengers the round trip fare is $\$ 40$. By comparison, the time for a one way flight from Saipan to Tinian is under 10 minutes while the one way ferry ride takes approximately 45 minutes. There is currently no scheduled ferry boat service to Rota or the northern islands from Saipan.

Perhaps the cultural aspects of Micronesia are the most interesting aspects of all.

Kiste states:

With few exceptions, matrilineal institutions prevailed throughout Micronesia. At birth, both females and males became members of their mother's matrilineage. Lineages were relative shallow, with a genealogical depth of three to five generations, and were the corporate groups that owned the land. As in Polynesia, siblings were ranked by the order of their birth, and sub lineages within a lineage were ranked by the order of their birth, and sub lineages within a lineage were ranked by the birth order of their founding sisters. The head of each lineage was its senior ranking male, and succession to lineage headship was matrilineal, that is, a male was succeeded by his younger brothers according to relative age, and they in turn were succeeded by their eldest sister's eldest son and his brothers. In most cases aggregations of lineages shared a common name and formed a social category or matriclan. The lineages of the same clan were scattered over several islands and usually were not linked by remembered genealogical connections. Nonetheless, clan members had a sense of common kinship, and the clan was exogamous, that is, spouses were acquired from outside the clan. The exogamous and dispersed clans functioned as large security nets. Islanders were obliged to protect and provide for their clan members, whether strangers or friends (in Howe, et al. 1994, pp. 14-15). 
It is interesting to note that on the high islands of the Marianas, Pohnpei, and Kosrae, and the low-lying Marshall Islands, certain clans (today they are called families) were of paramount chiefly status, and membership in these clans entitled one to privilege. Even as we enter the $21^{\text {st }}$ century, past European colonization has broken down much of the ancient clan structure, however, at least on Saipan, a half dozen or so families continue to control political and social life in the C.N.M.I.

In the Northern Marianas (Saipan, Rota, and Tinian) this hierarchy was greatly disrupted when the Spanish forcefully removed the indigenous Chamorros to Guam (Hezel \& Berg 1979, Peattie, 1988, Cunnigham, 1990, Howe, et al., 1994). Oral tradition has it that some Chamorros escaped and fled back to Rota where they hid from the Spanish and continued the traditions of their forefathers. This had led to the contention of many current Chamorros (born on Rota) that the Rotanese are the "purist" of the Chamorros living today in the C.N.M.I.

Three major factors have contributed to the dissolution of the cultural traditions of the Chamorros: First, the arrival of the Spanish, and the spreading of disease, reduced the original indigenous population from an estimated 50,000 natives to less than 4,000 , Second, the forceful removal of the Chamorros from the Northern Marianas to Guam (they were later allowed to return) where they were greatly overcrowded in squalid living conditions, and Third, the continued change in colonial masters with all the imported influences (i.e. inter-marriage, different cultural norms, new languages, disease, etc.) that these influences produce (Hezel \& Berg, 1979).

Two last areas of importance deal with the economic fluctuations and the political power of voting blocks in the Northern Marianas. "Since achieving Commonwealth 
status, the Northern Marianas has proceeded on its own course, quite separate from the rest of Micronesia, and had been experiencing an economic boom until the Gulf War situation in the early 1990s" (R. Kiste in Howe, et al., 1994, p. 328). After recovering from the Gulf War drop in the economy, the C.N.M.I. was again hit hard financially with the recent downturn in the Asian economies. Although several of the Asian economies are recovering, namely South Korea, the new prosperity has yet to trickle down to the government coffers in the C.N.M.I. (Saipan Tribune, May, 2000). This reduction in tax revenues for the C.N.M.I., has in turn, affected all government agencies of the C.N.M.I.. The Public School System (PSS) has approximately 500 employees. This is important because the vast majority of the PSS employees are registered voters in the C.N.M.I. You must be the holder of a U.S. passport, or be at least one quarter of Chamorro or Carolinian descent, and have resided in the C.N.M.I. for 45 consecutive days prior to any election, in order to vote (H. Del Rosario, July, 2000, personal communication). The PSS thus becomes the third largest voting block in the C.N.M.I., behind the indigenous Chamorros and Carolinians. Therefore, during budget allocations by the C.N.M.I. government, the PSS representatives act as a strong lobby for PSS budgetary interests. The Northern Marianas College, and to even a lesser degree, the Public Library, have small numbers of registered voters as employees, subsequently a smaller voice with the C.N.M.I. Legislature during budget allocations (H. Del Rosario, July, 2000, personal communication). Insufficient funds, naturally, are a reason for cutbacks in purchases and staff for any organization. This financial shortfall to the government of the C.N.M.I., coupled with the political emphasis on eliminating duplication of services, has directly 
led to the atmosphere for instituting a project such as the total resource sharing among collegiate and public libraries in the C.N.M.I.

Library Cooperation and Resource Sharing in Micronesia and Specifically in the Commonwealth of the Northern Mariana Islands

Referring back to chapter one of this research addressing the overview of Micronesia, what literature that is available sheds little light on libraries in this vast geographical area. During the pre-contact era, considered to be prior to 1521 , and the landing of Magellan on Guam, there appears to be no written records from Micronesia (Howe, et al., 1994, Hezel \& Berg, 1979). Obviously, with only the oral tradition being used throughout Micronesia, there were no libraries in the sense that we know them today, as repositories for the written word and for electronic databases. Nor is there a history of libraries in Micronesia from 1521, until shortly after World War II. All of the colonial powers active in Micronesia from the 1500s until World War II (Spain, Portugal, France, Germany, England, Japan, and the United States) appear to have been more interested in economic possibilities and strategic military bases, than in educating the indigenous peoples (Howe, et al., 1994, Hezel \& Berg, 1979, McHenry, 1975, Clyde, 1935). Clyde does relate that the history of formal education in Micronesia is not a long story.

In the Marshall Islands, beginning with the arrival of American missionaries in the middle of the $19^{\text {th }}$ century, formal education has been in the hands of such mission schools as the financial resources of the American Board of Boston permitted. Some of the Spanish priests, who established chapels in the Carolines and the Marianas in the days when Spain held the islands, were not unmindful of the educational needs of their converts. When Germany formally occupied the Marshalls in 1885, and the Carolines and Marianas in 1899, the educational facilities of these church schools were markedly improved. Nevertheless, education continued to be a by-product of the missionary effort (1935, pp. 103104). 
"During the German regime, educational advances were not lacking, for the Germans could boast of one hundred mission schools. However, the foundations of a public educational system were not laid until after the Japanese occupation and the subsequent establishment of the mandate" [by the League of Nations] (Clyde, 1935, p.105). "Accordingly, the first schools for native children were established by the Japanese throughout their mandate area in December of 1915, just a year after Japan had wrested the islands from Germany" (1935, p. 105). As Japanese children began to arrive in the mandated area in 1919, separate schools were built for them. The native schools were called "public" schools and the Japanese schools were called "primary" schools (Peattie, 1988, Clyde, 1935).

"Native children are admitted to school at 8 years of age. No tuition is charged, and they are provided with free textbooks and all necessary equipment. The regular course of study extends over three years with an additional two years for students of higher capacity" (Clyde, 1935, p. 106).

No mention of libraries is made in connection with this formal education as related by Clyde. Neither do Hezel \& Berg (1979), McHenry (1975), nor Howe, et al. (1994), make any mention of libraries until the post World War II era in Micronesia. In fact, the foremost scholar in the Marianas on the subject of the history of libraries in Micronesia, Nicholas Goetzfridt, at the University of Guam, stated that, "certainly there were a few small libraries created in Micronesia before the Library Services and Construction Act was extended to Micronesia in 1966, but even those pre-LSCA libraries came from the history I outlined" (2000, p.p. 7-8). Goetzfridt was referring to his earlier research which concluded that these libraries "ignored the protestant, white, middle-class exclusionary nature of the profession [library science]" (2000, p. 7). Even if a few, small, scattered libraries had been established in Micronesia prior to the post WWII era did they 
take into consideration the tradition of oral history, the social constructs, and the political constructs of Micronesia? Referring to these exact topics, Goetzfridt replies, "the answer to that question is, of course, nothing (2000, p.8, emphasis added).

As already explained, there is extremely limited written documentation on the history of libraries in Micronesia, therefore, I chose to discuss this topic with the C.N.M.I.'s Archivist, Mr. Herbert Del Rosario, in an attempt to gather as much knowledge as possible regarding this important period (post World War II to the present) relating to the research.

Today, there are college libraries (of one sort or another) on the Marshall Islands, the various islands of the Federated States of Micronesia, at Palau Community College in Koror, throughout the island of Guam, and on Saipan, Rota, and Tinian of the C.N.M.I. (H. Del Rosario, July, 2000, personal communication). Likewise, some form of public library exists on each of the aforementioned islands or island groups (H. Del Rosario, July, 2000, personal communication).

Although this research was designed to address resource sharing among public and collegiate libraries (and not to include school libraries for grades preK - 12) in the C.N.M.I., in some ways the school-library relationship cannot be ignored. To do so would leave out some needed continuity.

Review of the literature revealed that although the Japanese were the first colonizers to foster some degree of public education among the indigenous peoples of Micronesia, the extent of that education was formal schooling from grades $1-3$, with a very few locals, considered intelligent enough by their colonizers, to be taught another two years (Peattie, 1988, Clyde, 1935). Additionally, what literature is available did not 
mention libraries at all. One could assume that libraries may have existed to support the formal educational system in Japanese times, however, local oral tradition claims that such libraries did not exist, at least not for the indigenous people (H. Del Rosario, July, 2000, personal communication).

The issue of libraries in the C.N.M.I. is a spin-off of the issue of libraries in general for all of Micronesia. Teachers from the C.N.M.I. (called the Northern Marianas at the time of the 1952 meeting in Chuuk) were desirous to advance the field of Education. They knew from their formal education, and from the importance placed on libraries on the U.S. Mainland, that it was essential to have libraries established in the Northern Mariana Islands (H. Del Rosario, July, 2000, personal communication).

After cessation of hostilities of World War II in the Northern Marianas, the islands came under what was termed the Naval Administration. This lasted until 1947, when the Trust Territory of the Pacific Islands (the T.T.P.I.) was created by the United Nations, with the United States as the political body responsible for governing this vast region (T.T.P.I. Archives, 1947).

During the Naval Administration, from the end of World War II until 1947, a public library on Saipan was created and housed at the Findley Elementary School in what is now the William S. Reyes Elementary School, in the village of Chalan Kanoa. A second library was created and located at Saipan Intermediate School, presently the Hopwood Jr. High School. Finally, a third library was created and located in the village of China Town for use by American students (H. Del Rosario, July, 2000, personal communication). 
During the Trust Territory Administration a library was created for the Department of Education and located at Capital Hill on Saipan. The reason for the creation of this new library was that the headquarters for the T.T. had been moved to Saipan and the Department of Education felt a library was necessary at the new location (H. Del Rosario, July, 2000, personal communication). The Education Department made Hopwood Jr. High School the public high school on Saipan. Many years later, once the new Marianas High School was built, Hopwood became Hopwood Jr. High School and remained the only public junior high school on Saipan until the recent construction of Cha-Cha Jr. High School. The last fixed location library, actually the main public library for Saipan at the time, was created and housed in a building next to the cemetery in Chalan Kanoa. Shortly after construction, this library was severely damaged by a typhoon and is no longer in existence. In addition to the fixed libraries on Saipan during the T.T. times, the Department of Education also provided a Bookmobile that covered most of Saipan during the week days (H. Del Rosario, July, 2000, personal communication).

During the C.N.M.I. time, since 1978, the following libraries have been in operation: Marianas High School Library, C.N.M.I. Law Library, the Public School System Central Library, Hopwood Jr. High School Library, Mount Carmel Catholic School Library, the Northern Marianas College Library (founded in June of 1984) two public libraries subsequently destroyed by typhoons and abandoned, and the current JoeTen-Kiyu Public Library, which opened in late 1991, created from donations by two prominent Chamorro families (H. Del Rosario, July, 2000, personal communication). 
Realizing the myriad of potential problems involved with consolidation/cooperation of two or more organizations, the leaders initially involved with the concept of total resource sharing among collegiate and public libraries in the C.N.M.I., elected to work with only the NMC (college libraries) and the public libraries, in hopes of creating a workable solution with a minimum of challenges. Based on the success of the initial venture, other libraries in the C.N.M.I. would be approached for possible inclusion in the library consolidation/cooperation project.

\section{Conclusion}

This review of literature has started with a broad focus on reinventing government to eliminate duplication and waste, and then has narrowed the focus to look at a current private, and public, sector business practice commonly referred to as Business Process Reengineering. The focus was further narrowed to scrutinize organizational change, especially the change in organizational cultures during consolidation or cooperation. The focus of the literature review became even narrower with an historic overview of resource sharing among public, school, and academic libraries from the late $19^{\text {th }}$ century until the 1990s. To narrow the review of literature even tighter, modern day examples of public library, school library, and academic library resource sharing were studied. The review then presented essential pre-history, cultural, economic, and geographic information that the reader needed to understand the findings sections. The final focus examined the history of libraries in Micronesia, with specific emphasis on libraries in the

\section{C.N.M.I.}

Some common themes that arose during the review of the literature were 1) the importance of communication among all levels of an organization, especially during any 
change process; 2) the attitude of the people involved during a change process; and 3) the importance of leadership during any change process. It was interesting to note how these themes were manifested in the narrative, findings, and discussion portions of the final dissertation. 


\section{CHAPTER THREE}

\section{METHODOLOGY}

\section{Characterization of the Research Methodology}

The library consolidation and cooperation effort in the C.N.M.I. was played out in the 1990s. I systematically researched the process ex post facto starting in 1998, after most pieces of the consolidation and cooperation effort were in place. In December, 2000 , I began studying what key actors perceived to have been the major challenges in achieving total resource sharing among public and collegiate libraries in the C.N.M.I., how those challenges were addressed, and what types of leadership emerged in responding to these challenges. This information was used to construct the description of the process presented in the next chapter.

The research approach used to construct the account presented in the next chapter is somewhat difficult to characterize. In some sense, this study could be characterized as an action research project. An "action research study has as its essence the intent to change something, to solve some sort of a problem, or to take action" (Glesne, 1998, p.10). In addition, "the action research process is collaborative and inclusive of all major stakeholders with the researcher acting as a facilitator who keeps the research cycles moving" (Glesne, 1998, p. 14). This study could be considered action research because I played a key facilitation role in the project, especially during its early stages.

The project, however, was not initially conceived of as research-even action research; the research component was added after the change process was well underway and, indeed, in essence, completed. Although there is some precedent for calling such types of projects action research (See, for example, Yennie-Donmoyer and Donmoyer, 
1993), this is a less conventional view of what the term action research means and how an action research project should be undertaken.

My participant role, along with the study's focus on both the culture of the C.N.M.I. and the organizational "culture" of the libraries involved in consolidation, also suggests that this study might be characterized as ethnography. Participant observation is a standard methodological technique in ethnographic research and being a full participant is one option for playing the participant observer role (Glesne, 1998, Patton, 1990, Wolcott, 1994). Despite the fact I played what Glesne (1998) would call a participant as observer role, and what Wolcott (1994) calls an observer as participant role (these apparently contradictory labels are actually referencing the same sort of activity: the researcher observes while playing an active role in the organization.), and, despite the fact that some of the other data collections strategies I used might be labeled ethnographic, this is not an ethnography study in the classical anthropological sense of the word.

The most appropriate labels for this research are a case study (Yin, 1984, Stake, 1988) and narrative research (Polkinghorne, 1995). This project was characterized as a case study involving two entities located at three separate geographical sites. Patton (1990) states that,

Case studies are particularly valuable when the study aims to capture individual difference or unique variations from one program setting to another, or from one program experience to another. Regardless of the unit of analysis, a qualitative case study seeks to describe that unit in depth and detail, in context, and holistically (p. 54).

Case study is a very general term. This particular case study could also be characterized as narrative research. 
Polkinghorne (1995) distinguishes between the analysis of narrative and narrative analysis. The former term refers to the collecting and categorizing of the stories research subjects tell. The analysis of narrative, in other words, is simply traditional social science techniques applied to narrative data. What Polkinghorne (1995) calls narrative analysis represents more of a radical departure from the traditional norms of social science research, including qualitative social science research. When one employs the technique of narrative analysis, he or she attempts to analyze and present the data in narrative form. A researcher using narrative analysis operates more like an historian than a qualitative sociologist. Donmoyer, in fact, labels research that portrays change over time narratively as quasi-historical (June 2000, personal communication).

In this study, I employed techniques of narrative analysis to study a case with multiple components (Yin, 1984). For this reason the narrative case study label is most appropriate for characterizing the research methodology.

Description of Specific Research Procedures

\section{Site Selection}

Patton (1990) states that qualitative researchers tend to select each of their cases purposefully:

The logic and power of purposeful sampling lies in selecting information-rich cases for study in depth information rich cases are those from which one can learn a great deal about issues of central importance to the purpose of or the research ( $\mathrm{p}$. 169).

The Commonwealth Public Library has its main facility on the island of Saipan with branch libraries on the islands of Rota and Tinian. Likewise, the main campus of 
the Northern Marianas College is located on the island of Saipan with satellite campuses on the islands of Rota and Tinian. The very nature of the fact that each island played a significant, yet independent, role in the consolidation process mandated that each site be included in the site selection process to obtain the sort of information-rich case material described by Patton (1990).

Access

Obtaining access to all of the sites posed no problems. Glesne (1998) states that friendship is not an essential condition for conducting research; being accepted and trusted is. I am well known by most of the stakeholders involved and have a level of trust with them that an outsider almost certainly would not have. A case in point is the Mayor of Rota and the former Mayor of Tinian. I have met each of them on several occasions and these meetings paved the way for getting access to conduct the interviews for this study. An outsider almost certainly would have found getting access to these two wellinsulated individuals to be a difficult problem.

Because of the trust factor, I encountered no obstacles when attempting to arrange interviews with the mayors or anyone else, for that matter. I contacted the mayors' chiefs-of-staff, explained the situation, requested they act on my behalf, and set a date for the interviews. Access to public library personnel was obtained through the Commonwealth Library Director, and access to all NMC personnel was obtained through permission of the President of the College. Finally, each individual being requested to participate in the interview process was contacted by the researcher and given consent letters that they signed. 


\section{Researcher Role}

This research was, in essence, what Glesne (1998) calls a "backyard" (p. 26) type of study. By that she means the researcher is studying his or her own institution or agency. Although Glesne (1998) warns the reader that backyard research is "potentially fraught with problems" (p. 26), she also admits that this type of research can be valuable. After a thorough examination of the potential problems set forth by Glesne (1998), I judged that the potential benefits to be derived from studying my own organization far outweighed the potential problems.

Glesne (1998) also suggested that in backyard research "participant observation ranges across a continuum from mostly observation to mostly participation" (p. 24). On one extreme the researcher's role can be autobiographical due to his or her depth of participation, ranging to the other extreme where the researcher's role can be strictly observation (typical with psychologists who often carry out research entirely as an observer). Narratives, of course, can always be told from different points of view. I could have researched and written the narrative from either of the two roles described by Glesne (1988), or from somewhere in between. A case could have been made for me to write autobiographically, because much of the initial proposal was mine. Also, because I had networked with the Public Library Director, the NMC President, NMC Satellite Campus Administrators, and the Mayors of Rota and Tinian, I had been involved with all levels of personnel, and in all phases of the process of consolidation/cooperation. This would also support the narrative being written from an autobiographical standpoint. However, a stronger case was made for me to research and write as an interviewer and a participant observer because as the project gained momentum many others had to exert 
leadership for the library cooperation plan to be adopted, and even more actors were involved with implementation. My intense involvement was mostly during the initial phase of the project. Gradually my role became less of a participant and more of an observer. This justified the narrative being written from the viewpoint of an active participant, although not strictly as an autobiography. I have chosen to cast myself in a secondary role for the following reason: Although I was initially a key participant and instrumental in getting the project placed on key decision makers agendas, my role gradually became less centered and more observer than participant, especially on the two outer islands.

My role might also be characterized by using nomenclature from the field of anthropology and by pointing to studies in qualitative sociology. As noted above, there is ample precedent for ethnographic researchers playing an active participant role. Harry Wolcott's (1987) study, "The Teacher as Enemy," is an example. Gertrude McPherson's (1972) book, Small Town Teacher, is an example of a sociological work built around the researcher playing an active participant role (Donmoyer et al., 1995).

There are certainly limitations associated with having the researcher be an active participant. There are also advantages to being an insider and playing the direct participant role (Donmoyer et al., 1995). The advantages were especially strong in this situation where outsiders would have a very difficult (if not impossible) time in getting access to key stakeholders.

\section{Data Collection Procedures}

Although I indicated this study might best be characterized as a narrative case study, the data collection techniques were consistent with techniques of virtually any 
form of qualitative research. Specifically, I relied on interviews with key participants, an analysis of documents, and a review of survey results generated during the NMC accreditation process. As an insider, I also brought into play my personal observations and recollections; these, however, always were triangulated with other data.

The interviewees. I did use data triangulation throughout the study to strengthen the reported credibility (Patton, 1990). I interviewed seven of the eight major stakeholders involved in approving, planning, and implementing the library consolidation project. The list of interviewees included:

Title

Former President of NMC

Current President of NMC

Mayor

Former CNMI Librarian

Former NMC Satellite

Campus Administrator

Former NMC Satellite

Campus Administrator

Dean of Learning

Resources for NMC
Island

Saipan

Saipan

Rota

Saipan

Rota

Tinian

Saipan

Order of Interview Gender

3

2

6

1

5

4

7
F

M

M

M

M

M

$\mathrm{M}$

Unfortunately, unforeseen circumstances did not allow for an interview of the former Mayor of Tinian who was in office during the initial phases of library resource consolidation on that island.

The general interview strategies employed. I used one of two strategies in my interview process. I intended to use what Patton refers to as the standardized open-ended interview approach. This is one of three types of qualitative interviews described by 
Patton (1990). The other two types of qualitative interviews are: 1) the informal conversational interview and 2) the interview guide approach (Patton, 1990). I intended to use the standardized open-ended approach for a variety of reasons. First, in several cases I was only able to interview the stakeholder once, and the standardized open-ended interview approach assures that all questions needing a response will be covered (Patton, 1990). Second, in the majority of the interviews, I was limited by the amount of time allocated to me. The standardized open-ended interview approach was the most efficient (Patton, 1990). Third, I anticipated several of the stakeholders not agreeing to have the interview taped. Should this have occurred, the taking of detailed notes on what was said would have been facilitated by the use of a standardized interview schedule. (As it turned out, all participants agreed to the tape recording of interviews.) Finally, I anticipated that several of those to be interviewed would expect to see the actual interview questions beforehand instead of merely a topical outline (Patton, 1990), something that would not be possible if I used the conversation approach.

Although the standardized open-ended interview approach was used in most of interviews that were conducted, in several of the interviews the interviewee wanted to digress from the structured question. Often this desire to digress appeared to be a control issue, and, in these instances, I felt I had to accommodate the interviewee's preferences. I also realized that much richer information can be obtained when an interviewee strays from the standardized open-ended interview questions. Thus, on occasion, I switched to what Patton refers to as the interview guide approach. In this approach, the topics and issues are specified in advance, but the sequencing and wording of questions may varied (Patton, 1990). 
Regardless of the general interview approach that I used in a particular interview, I insured that all of the original questions were covered with each interviewee. By insuring that I covered all questions sent to the interviewee, I insured greater comparability of responses during the data analysis phase (Patton, 1990).

Three additional data collection procedural factors. Three other important factors concerning data collection, besides the interview strategies themselves, were: 1 ) how I contacted those to be interviewed, 2) the order in which people were interviewed, and 3) the site where each interview took place. With respect to the first point, I telephoned each potential interviewee and personally explained the reason for my research and obtained an impression of their willingness to participate. In the C.N.M.I. there is somewhat of a "distrust" of the written word, perhaps because for centuries all affairs were conducted in the oral tradition. It is generally a "norm" on Saipan, Rota, and Tinian to contact someone orally prior to any written communication in such matters where one expects some type of information or personal commitment. I followed up the telephone calls with letters and the formal written informed consent form for the potential interviewees to sign and return to me prior to another contact from me setting up the actual interview.

The order of interviews was important. I first interviewed the former Commonwealth Director of Library Services because his involvement closely paralleled mine in the initial stages of the library resource sharing project. Realizing that for this project to have any chance of success, the driving forces for the collegiate library and the public library had to be committed for the long-term, I first proposed the plan to the 
Commonwealth Director of Library Services. When his reaction was positive, we joined forces and each began using personal networks to analyze the feasibility of the project. It was important to interview the former Commonwealth Director of Library Services first because his knowledge of the timeline of implementation should have been similar to mine since we had shared the same implementation experiences. This interview was a way of triangulating insider information. The former Commonwealth Director of Library Services is the only other person, besides myself, that was actively involved with the library total resource sharing project on all three islands.

I followed up the first interview by interviewing the former and current Presidents of the NMC. Both are extremely supportive of the library cooperation/consolidation project, and I received a rich background data from these interviews. The remainder of the interviews were accomplished in the order of interviewee availability except for the Mayor of Rota. This individual is extremely powerful politically, and to avoid other interviewees from wanting to find out what the Mayor said and then simply agreeing, I interviewed the Mayor of Rota last.

Site selection for the interviews was a crucial element in the interview process. Generally I took my cue on this matter from the interviewees. The Mayor of Rota and the current President of the NMC desired to hold the interviews in their respective offices due to their busy schedules. The former Commonwealth Director of Library Services was then living on Guam. From past association with him, I expected him to want to hold the interview at his home, which was, in fact, where the interview took place. Likewise, the former President of the NMC suggested her home as the interview location. 
The former NMC Satellite Campus Administrators chose neutral sites, such as quiet restaurants on their islands. This choice stemmed from the fact that eating plays such a traditional role in meetings. It was not surprising that a restaurant was their choice of sites.

In the final analysis, as Patton (1990) stated that, "the particular evaluation situation, the needs of the interviewee, and the personal style of the interviewer all come together to create a unique situation for each interview. Therein lies the challenge of qualitative interviewing" (p. 357).

Additional data employed. In addition to standardized open-ended interviews, I used data generated by an information gathering form used during the accreditation process for the Northern Marianas College. Siddiqui (1989) feels that some type of baseline data needs to be gathered prior to any cooperation/consolidation of libraries because it is crucial that administrators know the extent of collections, etc. The baseline data gathered from the public and collegiate libraries in the C.N.M.I. were important because they helped to show the disparity between the central libraries, located on the island of Saipan, and the satellite libraries located on the islands of Rota and Tinian. Such disparity was an essential element or theme in any story of C.N.M.I. library consolidation/cooperation.

Other documents that were used in this research were (1) the memorandums of understanding (MOUs) that were developed among the various entities and the C.N.M.I. and the NMC, and (2) Public Library and NMC Library budgets. It is important to point out that very little written documentation, other than these documents existed. I have attempted to locate documents regarding the history of libraries in the C.N.M.I. and 
found extremely few. Anecdotal evidence suggested that most written records from the German and Japanese eras in the Northern Marianas were moved to the home countries and are currently unavailable or their whereabouts are unknown. Although extensive written records were kept during the Trust Territory of the Pacific Islands Administration of the Northern Mariana Islands, research has uncovered only minute references to libraries in the Northern Marianas (now the C.N.M.I.).

During the planning and implementation of the library total resource sharing project, few written documents were created other than the M.O.U.s. In light of this paucity of written documentation concerning the project, one of the primary data sources was the personal answers of the interviewees. In lieu of substantiated written data, confirmation of events and dates was personal answers to the interview questions. In the majority of cases these answers were triangulated with the answers of other stakeholders in the library resource sharing project.

Informally gathered participant observation data. The last form of "data" to be used was my personal observations and recollections of what transpired in various phases of the process. These recollections were shared with the former Director of Library Services at the Commonwealth Library and with other individuals, as appropriate, for triangulation purposes. Recollections were triangulated with interview data and written documents before they were reported as fact. At no time did I rely solely on personal observation in the absence of other data. If my personal recollections differed from the statements in an interview, I told both stories and made the differences clear. Whenever I speculated - I clearly labeled my speculations as such - about why stories differed. 


\section{Data Analysis}

In actuality, data analysis was started concurrently with data collection and enabled the researcher to focus and shape the study as it proceeded (Glesne, 1998). Final data analysis was made simpler by good strategies in the early stages of data collection. Initially, I kept a field log and jotted down important thoughts or ideas. I also kept a set of on-going analytic files. All notes were entered as soon as possible on a computer so thoughts could be expanded and clarified. As an overall strategy for analysis I attempted to create a "mega timeline" (Donmoyer, 2000, personal communication) with other timelines for the processes on Rota and Tinian embedded within the overall timeline.

I followed the procedures described by Polkinghorne (1995) for constructing the narrative that appears in Chapter 4. These procedures included:

1. The researcher must include descriptions of the cultural context in which the storied case study takes place.

2. The researcher needs to attend to the nature of the protagonists.

3. The researcher needs to be mindful not only of the general cultural environment and the person as embodied, but also of the importance of significant other people in affecting the actions and goals of the protagonists.

4. The researcher needs to concentrate on the choices and the actions of the central persons (the protagonists).

5. The researcher needs to consider the historical continuity of the characters.

6. The researcher must mark the beginning point of the story and the point of denouement.

7. The final guideline for judging the adequacy of a narrative analysis is whether it makes the generation of the researched occurrence plausible and understandable ( $p$. 76).

In addition, Polkinghome (1995) gives several steps in developing the narrative

from the data obtained during the research phase. They are:

- Specify the outcome to which the story will lead.

- Arrange the data elements chronologically.

- Identify which data elements are contributors to the identified outcome.

- Construct a plot outline.

- Fill in the outline with detail from data elements. 
- Adjust outline, where necessary, to better fit the data.

- Collect additional data, where necessary, to fill in "gaps" (p.77).

\section{Limitations of the Study}

There were several limitations to this study. First, were the biases I had as a participant. Much of the initial implementation of the total resource sharing among the public and collegiate libraries in the C.N.M.I. was my assignment; thus, I had a bias in wanting it to be successful. However, most qualitative researchers accept that "research is ideologically driven" and "there is no value-free or bias-free design" (Janesick, 1994, p. 212). Furthermore, this project, like the study of Yennie-Donmoyer and Donmoyer (1993), did not become a research study until there was clear evidence of success. This study was in no way an evaluation but simply an attempt to construct a process that has already been judged successful. It is important, however, that "the qualitative researcher early on identifies his or her biases... [so that] one can see easily where the questions that guide the study are crafted" (Janesick, 1994, p. 212). Like other qualitative researchers, I was not deluded that who I am would not make a difference in the outcomes of the study (Jansen \& Peshkin, 1992). Therefore, continued attention to the questions of subjectivity and objectivity were rooted in my research, as in any social science research that uses qualitative methods. I requested peers and my doctoral committee members to examine the data display and data analyses to provide outside perspectives that the findings indeed appeared to be an authentic representation of reality.

Though some readers may criticize the research on the grounds that I was such an active participant, and my observations and findings must be subjective rather than objective, I counter with the fact that there are significant advantages to this approach (Donmoyer, 1995). Foremost is the fact that more depth was obtained by being an 
insider, particularly in this situation where outsiders would have a difficult (if not impossible) time gaining access to several of the stakeholders.

The study may only be applicable to the C.N.M.I. because of the unique cultural aspects of the indigenous island leaders, and to the political situations on the islands of Rota and Tinian.

Finally, several of the stakeholders are in sensitive leadership positions and may or may not have been candid in their responses to the interview questions. This is coupled with the potential limitation that in the C.N.M.I., locals will often tell you what they think you want to hear. Douglas states it thus,

All competent adults are assumed to know that there are at least four major problems lying in the way of getting at social reality by asking people what is going on and that these problems must be dealt with if one is to avoid being taken in, duped, deceived, used, put on, fooled, suckered, made the patsy, left holding the bag, fronted out, and so on. These four problems are: (1) misinformation; (2) evasions; (3) lies, and (4) fronts (1976, p. 57).

Having spent fifteen years in the C.N.M.I., I overcame many of the barriers for outsiders. This is not to say that I am totally an insider, however, I know enough about the local culture, and I know the stakeholders to be interviewed well enough, that I was able to ascertain when a statement or comment they made in an interview was outrageous or erroneous. This was particularly true regarding statements about the library consolidation process because I played an active participant role. 


\section{CHAPTER FOUR}

\section{FINDINGS}

Janesick (1984) noted that a researcher must "find the most effective way to tell the story" (p. 215) implicit in the data he or she has collected. In order to tell the story of how collegiate and public libraries consolidated their operations and shared resources on the outer islands of Rota and Tinian and how cooperation was achieved to promote resource sharing among the collegiate and public libraries on the island of Saipan, in this chapter I will focus first on three contextual elements-the cultural, the economic, and the political - that influenced the story in significant ways. Then, I will describe the major events and how they unfolded on both the outer islands of Rota and Tinian and on the major island of Saipan.

\section{The Cultural Context}

"So I used also the cultural, you know, aspect of what I have in order for them [the politicians] to facilitate the development of this project" (Educator A, emphasis added).

The respondent who spoke these words was alluding to the fact that there are unique cultural ways of getting things done in the Commonwealth of the Northern Mariana Islands (C.N.M.I.). These cultural ways of operating are often referred to as the "Chamorro way." The culture is frequently referred to as Chamorro culture. Anyone who wants to understand the events that will be described later in this chapter must understand this unique cultural context. In this section, I will describe four important aspects of Chamorro culture in the C.N.M.I. that must be understood to make sense of the events surrounding the consolidation/cooperation of public and collegiate libraries on 
three island locations. These four aspects are: (1) male dominance of the culture; (2) the norm of secrecy with information; (3) an oral tradition; and (4) the norm of "saving face." Male Dominance of the Culture

Although historically most of the island cultures within Micronesia were matriarchal, today this in no longer the case in many Micronesian societies. Since the U.S. invasion and subsequent administration of Saipan near the end and after World War II, males have dominated cultural life in the C.N.M.I. (H. DelRosario, September, 2000, personal communication,). Males dominate the government, and males make most of the important family decisions.

Male dominance can be starkly illustrated by an incident I witnessed. During a congressional election on Saipan, an incumbent Congressman (a male Chamorro) created a special task force to inspect/audit the local college. The President of the College was a female Chamorro who was an outspoken advocate of legislative support for higher education. The Congressman ordered the President to appear before a legislative hearing on three occasions. During these hearings, the congressman proceeded to publicly humiliate the college president by questioning her integrity, by engaging in name-calling, and by insulting her. Had the president been a male this would never have happened. One Chamorro male simply does not publicly humiliate another Chamorro male. To do so would bring "loss of face" (see following) and/or retribution of some sort. When I questioned several prominent Chamorro male friends regarding the incident with the college president and the congressman, their answers were all the same: "It happened because she was a woman." 
The Norm of Secrecy with Information

Secrecy with respect to information is another cultural aspect that comes into play in the story that will be told later in this chapter. This cultural characteristic can be seen most clearly in certain Micronesian societies that have not been impacted as severely by the United States culture as the C.N.M.I. For instance, the Pohnpeians, a Micronesian cultural group that lives approximately 900 miles south southeast of Saipan, consider knowledge as the inner context of a person. A close Pohnpeian friend of mine explained it like this. The possession of knowledge is what continues to give life to a man's body. A man who has knowledge is full of life and is useful to the village. If a man tells all he knows then he becomes empty, like an empty fishing net. He is no longer of any use to the village. Once a man loses all of his knowledge then he will get sick and die. (P. Peter, August, 2000, personal communication).

In part because of the westernization of the C.N.M.I. resulting from the United States presence on the islands, the politics of concealment is not as obvious in Chamorro culture as it is among certain other Micronesian islanders, such as the Pohnpeians. However, residue of the concealment strategy can still be found among the Chamorros of the C.N.M.I. An illustration of the presence of this cultural norm was provided by a prominent male Chamorro friend when I suggested we film the making of traditional medicines. "Jim, this would be very difficult to accomplish because these types of things are secret. They are handed down within the family or to other very trusted individuals" (H. DelRosario, September, 1998, personal communication).

\footnotetext{
${ }^{1}$ Reconstructed Quote
} 


\section{An Oral Tradition}

The culture's reliance on oral tradition is another critical factor in understanding the story told in this chapter. It was not until western missionaries arrived in Micronesia in the mid 1850s that written languages began to be created in the various island groups, and not until the German Administration of Saipan, in the early part of the $20^{\text {th }}$ century, that written language and schooling became even marginally important in the Marianas. One scholar noted that during the Japanese Administration, which lasted from 1910 to 1944, indigenous people on Saipan were only receiving approximately three years of formal schooling (Russell, 1983). It was only after the Trust Territory of the Pacific Islands was formed after World War II, with the United States acting as administrator, that the Marianas had sufficient schools to accommodate universal education through the eighth grade. Marianas High School was not built until 1959.

Needless to say, the historical absence of a written language until Western religious missionaries arrived in the 1800 s and the culture's reliance on oral tradition have implications for how libraries are valued (or not valued) in the C.N.M.I. As late as 2001, a highly respected Chamorro educator in the C.N.M.I. said to me, "Jim, Chamorros don't read books unless they are required to. Nearly everything we deem important is taught orally by someone in the family or the community",2 (Educator B).

This statement suggests the value most locals in the C.N.M.I. give to libraries and their contents.

The Norms of "Saving Face" and Respecting Elders

The norm of "saving face" is also a critical cultural component in the Marianas. The Mariana Islands and her people have been subjugated by the Spanish, the Germans,

\footnotetext{
${ }^{2}$ Reconstructed Quote
} 
the Japanese, and the Americans from the early 1500s until Commonwealth status was granted and the Northern Marianas became part of the United States' political family. The legacy of these colonial powers is less than admirable, however, each colonial power provided a different kind of cultural infusion to the indigenous population. The Japanese instilled, or at least strongly reinforced, the concept of "saving face."

In the Northern Marianas, as in Japan, the notion of "saving face" coexisted and interacted with a cultural tradition that predated the Japanese occupation: respect for elders or the manamko. Prior to the United States Naval Administration of the region, the respect for elders was so strong that families would keep the bones of their relatives in a place of honor in their homes. Eventually this practice became less commonplace-in part because the United States discouraged the practice — but respect for elders, both those who had died and those who were still living, remained a part of Chamorro culture well past the Naval Administration period. Today, as a result of continuing westernization, respect for the manamko may at times be more superficial than it was in the past when respect for elders was a deeply felt cultural norm. Nevertheless, even in a weakened form, the norm of respecting elders remains a significant part of Chamorro culture and, together with the norm of "saving face," figures into the resource sharing storyline that is presented below.

The Economic Context

Although understanding the cultural context is essential for the reader to make sense of the findings, it is the economic context that was the primary factor in setting the stage for resource sharing. In the 1990s, a number of events led to an economic crisis in the C.N.M.I.: (1) the Gulf War precipitated a drastic drop in tourism; (2) the C.N.M.I. legislature passed what is known as the Article Twelve legislation designed to target 
established foreign investors, especially the hotel industry, and this legislation led to diminished investment by foreign investors; (3) some Asian economies, most notably South Korea and Japan, went into severe recession that led to a further decline in tourism; and (4) there was a significant number of business license non-renewals by small time foreign investors, especially South Koreans, that was followed by many of these same investors/businessmen closing down their businesses and departing the C.N.M.I.

These chaotic events led to a range of negative consequences affecting all of the C.N.M.I. such as: (1) insufficient funding to meet the established C.N.M.I. budget, (2) various government entities not contributing to the C.N.M.I. retirement fund, and (3) the departure of the C.N.M.I.'s librarian. The last event caused disarray within the public library system, nearly causing the closure of the public library for a third time in two decades.

\section{The Political Context}

As was noted in the discussion of the cultural context, the Northern Marianas region in the past was occupied by a number of foreign powers. For better or worse, each power contributed something to Northern Marianas society. The Americans brought democratic procedures.

Unfortunately, United States citizenship was granted with the stroke of a pen and without any formal schooling or mentoring in how to make democratic social organization work. President Gerald Ford, on 4 November 1986, granted citizenship to "certain qualified Trust Territory citizens, and others became U.S. citizens" (McPhetres, 1997, p. 69). One day, in other words, the local people were aliens; the next day they were United States citizens expected to govern themselves democratically. Not 
surprisingly, democratic procedures often were transformed by elements of the indigenous culture.

For instance, in the C.N.M.I. the political arena is highly personal. This occurs, in part, because of demographics. Because there is a relatively small group of Chamorros in the C.N.M.I., coupled with the fact that most Chamorros tend to marry other Chamorros, many of the duly elected government officials are part of the same family network. One interviewee alludes to this phenomenon in the following quotation:

Politics in the C.N.M.I. are more a function of family relationships and personal loyalties than of political party affiliation. Although the two major parties in the C.N.M.I. call themselves Democrats and Republicans, there is no similarity in platforms or ideology to those same parties on the mainland U.S. (Educator A).

A former President of NMC also reinforced the familial nature of politics in C.N.M.I.

During one of my interviews with her, she stated:

The size of one's extended family, instead of personal qualifications, is often the criteria in determining who becomes a candidate in local elections, obviously because the larger the extended family the more influence a candidate has and the more votes he or she is able to deliver on election day. This is especially true in the case of the governor and lieutenant governor" 3

Other cultural norms, such as the "saving face" norm and the respect for elders norm, also, at times, get played out in the C.N.M.I. version of democracy. In part because of these norms, the extensive networks of family relationships that operate within the local government can at times function in ways that westerners almost certainly would characterize as blatant nepotism. A recent example of this is the court case wherein Senator Ricardo S. Atalig was found guilty of wire fraud and misappropriating C.N.M.I. government funds. This resulted from Senator Atalig agreeing with another Senator, Jose Dela Cruz, to hire each other's relatives but not

\footnotetext{
${ }^{3}$ Reconstructed Quote
} 
requiring the relatives to do any work. In fact, Marjorie Dela Cruz, daughter of Senator Dela Cruz, was actually a full time student at the University of Guam located some 120 miles south of Saipan while being employed by the Saipan government. Senator Atalig certified Ms. Dela Cruz's time sheet every two weeks then had the payroll funds electronically transferred to Marjorie's account through the Bank of Guam (Saipan Tribune, April 26, 2003).

Thus, the familial-oriented political context of the C.N.M.I. is significant in the story of resource sharing, especially in light of the cultural factors discussed earlier. The hierarchical nature of Chamorro culture, for instance, is played out in governmental contexts and made all the stronger-and all the more personal-because government officials frequently are members of the same extended families.

The fact that many governmental officials are also related with each other also makes it difficult to draw a definitive line between the personal and the professional. One consequence is that the same sorts of gender relationships (i.e. male dominance) which are played out in family life, and in the larger cultural context, also tend to get played out in governmental operations. This means that even though women are officially permitted to hold high-level government offices, they do not necessarily have the same sort of power and respect that men would have in the same office.

Finally the familial dimension of politics in the C.N.M.I. often means that there is a highly personal dimension to the way that the culture norm of "saving face" gets played out in the political domain. If one offends one member of the government-especially a high-ranking official - one automatically offends a large number of other extended family members. There is also an insider/outsider dynamic that is reinforced by the 
existence of familial networks in the government. This insider/outsider dynamic is particularly strong when non-Chamorros become actors in the political process. NonChamorros, especially if they are outside of the formal governmental structure, often have difficulty influencing the political process no matter how good their ideas might be.

Because the concept of resource sharing needed to be supported by those in power if it were to have a chance of being enacted, all of the political factors listed above are important in understanding the resource sharing/consolidation story that is about to be told. Because of the familial relationships within the government and the hierarchical relationships that these familial links reinforced, the support of those at the top of the family/government hierarchy was especially important.

Library Resource Sharing on Saipan and the Outer Islands:

\section{A Chronology of Significant Events}

This section describes the chronology of significant events. These events also are summarized on timelines found in Appendix B.

The Genesis of the Resource Sharing/Consolidation Idea

The genesis of the idea of total resource sharing can be traced back to the late 1980s and early 1990s. The impetus for rethinking the viability of having separate collegiate and public libraries was a budget crisis brought on by the C.N.M.I. government's decision to establish small NMC satellite campuses on the islands of Rota and Tinian. Unfortunately, no capital improvement funding was provided by the C.N.M.I. government to assist in creating these campuses.

Therefore, the President of NMC at that time believed the decision to establish satellite campuses was problematic. The challenges this decision posed were 
compounded by the fact that, from the President's perspective, at least, funding for the original Saipan campus was less than adequate and had always been so since the college was formed in 1981. Indeed, when she was named the first NMC President, she headed an institution that, in reality, had no facilities. The President started the institution with mostly adjunct instructors and by convincing the Marianas High School administrators to have college classes taught on their campus, mostly at night. The NMC President then badgered and cajoled the local legislature until it approved the use of the old and condemned World War II U.S. military hospital as the site for the newly created Northern Marianas College (A. McPhetres, June, 1991, personal communication).

Despite her misgivings, the President was an astute politician and agreed to the establishment of satellite campuses on the two outer islands. Her greatest fears were realized, however, when no facilities were provided for the creation of these satellite campuses. It was, to quote the folk-philosopher, Yogi Berra, deja vous all over again.

This time the President worked with the Mayors of the outer islands to have condemned structures converted into campuses. However, there were virtually no funds available to convert condemned buildings into college campuses. In addition, there were no funds to support programs in the less-than-adequate facilities. Thus, the creation of the satellite campuses aggravated the funding problems that had plagued the NMC since its founding. Because of funding difficulties, the first president began thinking in terms of consolidating limited resources. Her thinking included the idea of consolidating college and C.N.M.I. (public) libraries. She began campaigning aggressively for this option on the outer islands in the early 1990s, particularly after the Western Association of Schools and Colleges (WASC) Accreditation Team report was released in late 1990. 
Alternative Versions of the Genesis Storyline

Interestingly, the storyline presented in the previous section is not the story that most of the interviewees told about the genesis of the library consolidation/cooperation idea and initiative on either of the outer islands. Rather, in nearly every case, the interviewees took much of the credit for conceptualizing and/or implementing the library resource sharing project. For instance, this is what one educator from Rota said about the origins of the resource sharing initiative:

I figured, looking at all the money that's being spent on this island, I felt that it's about time that we got our resources together and try to build one library that would really help this community. That includes the college, even the high school students, and the community. And so I felt at that time it was the best idea and encouraged, at the time, the President that we should really pursue this concept. And I believe it originated ...I remembered at the time when there was an accreditation team that was supposed to come back in the early ' $90 \mathrm{~s}$. If I'm not mistaken 1991-1992, somewhere on [sic] that time. And so that's how it originated (Educator $\mathrm{C}$ ).

This same respondent later added:

Like I said, ...this thing [the resource sharing project] is like a pet to me. That's why I put a lot of energy into this thing, even to securing the land. I took this as a pet for me and I worked it out together with the [political] leadership (Educator C).

A respondent on Tinian replied to a question about the origins of the resource sharing initiative on his island in much the same way, though, in his account, he and his fellow Tinians were the source of the resource sharing idea; the President of the NMC was not even a supporting player in his storyline. He said:

That started back in 1993 . We, the NMC and the community of Tinian, did a project where we did, in fact, combine the resources of the college and resources of the community of Tinian to put together a learning resource center for the benefit of not only our NMC students, but also for the public as well (Politician A).

When I asked this respondent on Tinian to explain his role in the early process of total resources sharing, his response was: 
My role was very crucial at that point in 1993 , because I was constantly in conflict with the [academic] deans. As the Campus Administrator, I was responsible for coordinating the types of programs that the college should offer to the community. Again, that conflict resulted in us combining resources to ensure the integrity of the courses and help the students in finding resources. So it was crucial that I looked for resources at that point to prove to the - to the President and the Board of Regents and the Deans that -- that we can actually offer these courses if the resources are here (Politician A).

Legislators also were not averse to claiming a good share of the credit for the library resource sharing idea. Below is the library resource sharing story as recounted by one politician.

Because I was the Chairman of our Senate Committee [in the C.N.M.I. Legislature], you know, during those days, I play [sic] a great role in addressing Rota capitol improvement (CIP) need [sic] because during those days, ... the money was not readily available. Whatever little money we have [sic] that we could use for capital improvement have [sic] to be appropriated first. It's a very competitive process during the old legislature time and I was very much instrumental in addressing Rota's need during those days (Politician C).

The reconstructed histories exemplified in the quotes above represent more than the human tendency to be a bit egocentric. The reconstructed histories also say something about Chamorro culture and the tactics that those who developed and promoted the library consolidation/cooperation idea consciously used to advance their idea through the system.

For instance, as was noted in earlier sections of this chapter, Chamorro culture undervalues females and non-Chamorros and highly values elders and those who hold high-level positions in the hierarchy. The norm of "saving face" is strong within the Chamorro culture and is linked to the culture's respect for hierarchy. This means that it is especially important that those who hold high-level government positions are allowed to "save face." 
The female President of the NMC was aware of all of the above cultural/political dynamics and acted accordingly. For example, she knew that, as a female, the idea for resource sharing could not be perceived as her idea; it would have a far better chance of getting implemented if the idea was attributed to those with formal positional power, i.e. high ranking officials and the familial/political networks with which the officials were associated. She also knew that, when she sent me to represent her on this issue, she needed to remind me that, as a non-Chamorro, I had to go out of my way not to appear to be in any way the source of the library cooperation/consolidation idea. Consequently, on one occasion, in 1994, when she sent me to the island of Rota to talk with the Mayor, she explicitly briefed me about what I should and should not do. She said something like the following:

Jim, you have been here long enough to know how things work on the outer islands. It is critical that we get Benjamin's [Mayor of Rota] support on this resource-sharing project. I want you to go to Rota and work with the NMC Campus Administrator and the Mayor. Explain the value of the consolidation to the community as well as to the college. I have already been to Rota and visited with the Mayor and he is already thinking along these lines. Choose your words carefully and be supportive that the idea came from the Mayor. Once the discussions are complete draft me a memorandum of understanding and I will have our legal council review it. ${ }^{4}$

To summarize: The NMC President, who, in fact, had created the initial vision of total library resource sharing in response to some rather dire fiscal problems, had grown up within and consequently understood Chamorro culture and the way to get things done politically in this cultural milieu. Consequently, she went to great lengths to allow others to take credit for the library resource sharing project and to mask her own contributions and the contributions of her surrogates. This masking process helps explain why I was

\footnotetext{
${ }^{4}$ Reconstructed Quote
} 
told different stories by different protagonists when I asked people about the origins of the library resource sharing plan.

One Constant in all of the Outer Island Storylines: The Outer Island Mayors' Power

One fact that was acknowledged in all the interviews conducted on both of the outer islands-and also by many Saipan interviewees when they talked about the outer islandsinvolved the considerable power of the Mayors of Rota and Tinian. Everyone agreed that library consolidation/cooperation would not have happened on either outer island without the whole-hearted support of the respective Mayor. A respondent on Rota, for instance, stated:

From our standpoint here for outsiders to come in and dictate to us is not going to work. It's got to come from this island and if the mayor thinks that this one [idea] is good for these people then he will go that direction. (Educator C)

When asked to elaborate on his comments about the mayor, this respondent said:

Well, I'm going to tell you, Jim, I guess if you own a place or you belong to a place...it's nature [sic]. It's natural that you feel you're powerful and especially when you hold such a position being the Mayor of this island, you are going to be the most powerful person (Educator $\mathrm{C}$ ).

A politician on Rota also alluded to the power of the Mayor when he discussed why some initiatives failed: “The central government don't [sic] understand that this decision have [sic] to be made by the local people" (Politician C). Later, this politician made it clear that when he used the term "local people" he was referring specifically to the Mayor of Rota.

A Rota educator who was describing the political climate during Mayor Inos' administration that began in 1992 and ended in 1995, and the administration of Inos' successor, Mayor Manglona, also alluded to the power of the Rota mayor. This respondent indicated that in the early 90s he went ahead and asked the President of NMC for permission to identify a site on which to build the new campus. He elaborated: 
I remembered the old campus being up here next to the hospital and that building [the old campus] was already condemned at the time. So we were looking at the best site and finally was [sic] able to locate one at Ginalangan [geographic site on Rota]. And the idea there was to perhaps also build the [public] library up there together with the college. Unfortunately, that one did not work out. For some reasons our leaders [the mayor and municipal council] are very much concerned about the location down here at Tatachog [a location midway between the two major villages on Rota]. So finally, they [the mayor and municipal council] decided that the college should be built down here at Tatachog... But then... Mayor Manglona took over. And so we finally, we approach [sic] them [Mayor Manglona and the municipal council] with this concept and he [Mayor Manglona] was in favor of the concept (Educator C).

A respondent from Tinian suggested that the Tinian Mayor's support was absolutely essential for getting the library resource sharing strategy implemented on Tinian. For example, he spoke of the importance of "convincing the Mayor that it [resource sharing] is the politically correct thing to do" (Politician A). At another point, this same politician spoke of the need to make not only the mayor but also other highranking politicians believe that the idea you are promoting is actually their idea. When asked about how the library resource sharing idea got implemented on Tinian, he said the following:

That's the secret. You keep with these people [the mayor and the municipal council] and you be persistent and you, if you have that high level of energy, you will find the resources are out there. It's just putting them together and making people believe that what you're doing is worthwhile; that what you're doing is for the community and you run to these politicians, these policy makers who are making the policies and make them believe that their decisions are very important. Make them part of this plan. If they claim ownership to the plan, then it's supported, ... and it becomes theirs. Don't claim it for yourself. (Politician A, emphasis added).

A respondent from Saipan reinforced the point about the outer island Mayors' power that was made time and time again in interviews that had been conducted on the outer islands. This respondent, who did not live on either of the outer islands but knew how politics worked in both places, said the following: 
I think the two highest levels of political individuals...to gain support and acceptance, and ownership into such projects are the two Mayors, which are seen as the primary caretakers of the activities and government agencies...in these two islands. The Mayor really is the key individual in these two islands. Being the caretaker, he is the one that calls the shots as to whom should get involved. When it comes to the interests of the people of Tinian and Rota in relation to governmental activities... it is appropriate and a very, very respectable [italics added] way to go about in terms of dealing with the Mayor's office first and foremost. And this is not to be seen in a negative action (Educator B) An additional comment made by another respondent, Educator D, can serve as a

summary statement for this section of the chapter. During my interview with Educator D, he said: "The role of the Mayor on each island is very central in the sense that they make a decision in everything."

How the Mayors' Power Impacted the Library Resource Sharing Story

The power of the two outer island Mayors affected the NMC President's decision about where to begin the library consolidation effort. Because power in the outer islands was vested in single individuals (unlike on Saipan where power tended to be distributed and a coalition of diverse individuals and groups was required to get anything accomplished), the President of the NMC decided to make her initial consolidation moves on the outer islands. This decision was influenced by the fact that she had access to, and influence with, both outer island Mayors by virtue of her family connections. She said during her interview:

Fortunately, both groups [i.e. both mayors] are either my first cousins or my nephews, my relatives. So I used also the cultural...aspect of what I have in order for them to facilitate the development of this project. There was some convincing to do; for them, twisting their arms to reprogram their funding, to assign people to work for our library, and also to give us the facility because we didn't have the facility then. Assigning the Public Library as part of the Northern Marianas College ...the mayors endorsed that and it was also pushed by the senators and legislators from those two islands. We have to use the culture. We also have to use politics (Educator A). 
Thus can be seen the importance of the familial relationships influencing political power combined with cultural norms in the C.N.M.I.

Wielding the Weapon of Accreditation

Of course, accounts of complex social phenomena-if they are not merely gross oversimplifications of what actually occurred - seldom involve only a single influential factor. Such is the case here. Certainly the power of the outer island Mayors and the access the NMC President had to these powerful individuals had a significant impact on her decision to begin the library resource sharing initiative on Rota and Tinian as well as on the success of these initial moves. But there was also a compelling need to move quickly to bolster the library facilities available to students taking classes on the two outer island campuses, and, hence, a compelling case could be made to key decisionmakers: unless the existing deficiencies began to be addressed, re-accreditation of the outer island campuses was in jeopardy.

Thus, accreditation figured into the President's decision to begin the library resource sharing process on the outer islands. Accreditation-or, to be more precise, the threat of loosing accreditation-also was a potent weapon that the NMC President used to convince the Mayors and other politicians that resource sharing across collegiate and public libraries on Rota and Tinian was an absolute necessity given the limited resources available to support collegiate education on the two outer islands..

Deficiencies in the outer island libraries, in fact, had been highlighted in an accreditation report issued by the WASC (Western Association of Schools and Colleges) accreditation team who had visited the NMC in the early 1990 s. It was reasonable to assume that, if this issue was not addressed, re-accreditation would be put in serious 
jeopardy. The President confirmed that she quite consciously used the threat of losing accreditation of the outer islands' campuses as a selling point in making the case for consolidating collegiate and public libraries on Rota and Tinian. When asked if this was the case, she replied:

Yes, and in fact, that's one of the reasons why I used that [accreditation] as part of the requirement that we will not offer any course unless we do have a good...learning resource center in order for us to provide similar or adequate services to the students of Rota and Tinian because of the accreditation requirement. We cannot offer programs on those two campuses unless they have the same type of quality or similar quality as we are offering on Saipan (Educator A).

\section{Fortuitous Circumstance: The Case of Rota}

Often, even in a political environment where one person holds most of the power and where there will be dire consequences if the person in power does not implement a particular proposal, the proposal still may not get implemented. Frequently, other fortuitous circumstances must arise for action to happen. The story of library resource sharing on both of the outer islands involves such fortuitous circumstances, though the particular fortuitous circumstances differed in each case.

On Rota, the fortuitous circumstance was an act of nature: A typhoon struck Rota in 1998 and destroyed the small Public Library and damaged the small NMC Rota Library. The destruction of the Public Library virtually forced the Mayor to take some sort of action. The typhoon was also the primary factor in allowing Rota to obtain sufficient funding to underwrite construction because Federal Emergency Management Assistance (FEMA) personnel recommended federal disaster funds be allocated for disaster relief. One respondent said of the typhoon:

That is the main reason, really, that also prompted the Mayor [Manglona] to seriously look into this concept [of public and collegiate resource sharing] and combine the resources; joined together so we can have just one library. The 
money is to be taken from FEMA, and at the same time, I believe we have local funding plus additional federal funding that would support the new library (Educator C).

Of course, the need to build a new public library to replace the one that the typhoon had destroyed did not require that the public and collegiate libraries had to be combined in one facility or that other sorts of resource sharing needed to occur, as eventually happened in Rota. The resource sharing seed, however, had been planted in the Mayor's mind years before the typhoon hit by one of his relatives, the President of the NMC. In addition, as a stopgap measure after the typhoon had destroyed Rota's Public Library and damaged the College Library on Rota, the Mayor had helped engineer a temporary form of library facilities sharing: In part to insure that the Rota campus did not loose its accreditation (this was one of the NMC President's selling points for consolidation) and also to keep the public library open, a consortium of representatives from the college, the Public Library, the public schools and the Mayor's office proposed, temporarily, housing both the collegiate and public libraries in the island's high school library. When some public school officials on Saipan appeared to balk at this idea, the Mayor of Rota called the secondary school principal and "arranged for" the temporary consolidation plan to be implemented.

This stopgap solution established an actual precedent for the resource sharing idea that the NMC President had been advocating. This precedent helped establish the viability of the resource sharing notion. The notion was made all the more appealing by the fact that the island received fewer FEMA dollars than would be needed to do all the rebuilding that would be required to repair the typhoon's damage. In essence, this was the choice facing the Mayor and other key decision makers: This island, with a 
population of approximately 2500 , could have two inadequate libraries, or it could have one far more impressive one. The correct choice seemed apparent to those in power, especially in light of the lobbying that had been done and the precedent that had been set. Indeed, there were even plans, at one point, to also include the Public School Library into the combined library structure, though this plan was undermined by actions of the School Board in Saipan.

\section{A Different Set of Fortuitous Circumstances: The Case of Tinian}

In contrast to a natural disaster being the impetus for the resource sharing project on Rota, the fortuitous circumstance on Tinian was man-made. In 1998, Tinian's Mayor, Mayor Borja, selected the NMC-Tinian Campus Administrator to become his Chief of Staff. In his interview for this study, this individual explained the significance of this appointment for library resource sharing on Tinian:

My influence after Mayor Borja took office in 1998... the vision for the master planning of the college, the vision for having a big learning resource center, and all those visions in education and post secondary education were carried with me to the new administration of Mayor Borja. And Mayor Borja embraced that as part of his vision for Tinian...to be known as an educational leader. It was really hard leaving Tinian campus because I had all these plans for Tinian campus...but I think it was a blessing in disguise for the college because I was in a position to influence the Mayor and some of the [other] politicians in making decisions for resources. I was able to facilitate, again, for the college and especially the learning resource center. I was positioned in a way to help whole sectors of the community, but especially...post secondary education (Politician A, emphasis added)

Two Happy Endings for the Outer Islands Library Resource Sharing Story

In fact, the chief of staff quickly convinced the Mayor and other Tinian politicians to build a learning resource center that would serve both the Tinian branch of the college and the Tinian public. Thus, by 1998 , on both Tinian and Rota the pieces were in place for collegiate and public library consolidation. In each case the resources that were 
shared included the facilities in which the two previously separate libraries were now housed.

\section{Meanwhile Back on Saipan...}

The Saipan story also had a happy ending. The final solution, however, had a quite different form than the single-facility ending in both outer island stories. In addition, the Saipan library resource sharing storyline is quite different from the storylines of how library resource sharing came to be a reality on the two outer islands. In the Saipan story, there is no character like the (almost) all-powerful Mayors of Rota and Tinian. There also is no natural disaster to set the stage for rethinking the library structure and no representative from the college in an influential governmental position to advocate for the library resource sharing notion.

Rather, the Saipan story is very much a story of behind-the-scenes maneuvering that occurred without the knowledge of, or official sanction from, official policymakers in the government. Policymakers do not enter the Saipan version of the library resource sharing story until near its end when resource sharing is, in essence, already in place and an obvious success. Their role, at that point, is simply to endorse (and bless) the idea. It's all in the Timing (and the Right Personnel) Although the President of the NMC was promoting the library resource sharing idea on the outer islands during the early 1990 s, not much could be done about library resource sharing on Saipan until the middle of the 1990s. During her interview, the President of the NMC explained why. She noted that she and I had discussed the idea of combining public and 
collegiate libraries on Saipan soon after I became Director of Library

Services in 1994. She then said:

It was a very good idea for us to do that since it's just a very small place [Saipan]. However, ...because of the law that creates a separate Board for the Public Library, and it was a separate [autonomous] entity, it was not appropriate for us to make the move in trying to run it for them. If you recall, I indicated to you that it would be best for them to come and ask for our assistance. Nothing happened. They were having a tough time trying to recruit a Director for the Public Library. They would hire a director and after a year or so the director would quit. So none of these ideas of trying to work closely with the Public Library [on Saipan] materialized until they hired the director that eventually became the Director of Library Services at Northern Marianas College (Educator A).

At another point in the interview, the President said:

It took us almost six years [until 1998] to get this together. And the reason it took so long is because of the inability of the Public Library... to hire people that agreed on procedures or were stable [in staying on Saipan and in the library system]. But once they got the right individual in place then we were able to discuss this [cooperative effort] (Educator A).

The "right individual" was hired in 1996 to fill what previously had been a revolving door (and often vacant) position: Commonwealth Librarian. The newly-hired Commonwealth Librarian saw the wisdom of the resource sharing initiatives on the outer island and he and I, in my role as Dean of Learning Resources of the NMC, began to work together to jointly funnel resources to the two outer island libraries that had, at this point, begun to take initial steps toward implementing the resource sharing concept.

The Commonwealth Librarian said the following about some of his early efforts to help the outer island libraries:

I thought that a small new book collection would work quite well so I tried to set that up and I found funding where I could provide a leased book collection. I arranged for a system so books could be sent there [to Rota and Tinian]. I also started... to order extra titles here and there on an occasional basis, especially for something I thought was very appropriate or significant so that there would be additional books for Tinian and Rota. But this was just a small drop in the bucket, 
so to speak. But it was something we could do within our own authority and control (Educator D).

I was also funneling whatever resources I could to the outer island libraries to build the capacity of the libraries for accreditation purposes and to support the consolidation effort. For example, I set aside money from the annual general library budget to buy materials and equipment to be sent to the outer islands. I also sent a professional librarian to the NMC Tinian library. This person was the first professional librarian on either outer island on a full-time basis.

As it turned out, the success of the consolidation efforts on the two outer islands provided a model for greater cross-library cooperation on Saipan. Of course, as might be expected, there is more to this story than the triumph of a good idea that had been vetted on both of the outer islands. Good ideas, in and of themselves, seldom triumph in politically complex contexts like the public policymaking arenas of Saipan.

\section{Creating a Consortium on Saipan}

In at least one respect, the Saipan and Outer Island stories are the same: Just as fortuitous events helped accelerate the resource sharing project on the outer islands, so too did one crucial event spur the advancement of the resource sharing project on the main island. The Public Library had for some time been receiving funds from a Library Services and Technology Grant sponsored by the United States Government. When renewal time for this grant approached, the new Commonwealth Librarian discovered that the grant was about to expire and that the Public Library stood to lose many thousands of dollars of desperately needed funding. Realizing that the Public Library had no cash reserves and not enough in-kind contributions toward renewal of the grant, the Commonwealth Librarian turned to me in my capacity as Dean of Learning Resources at 
NMC for a brainstorming session. The Commonwealth Librarian describes what evolved out of that session:

One of the bases for justification for the grant was to serve areas that are under served or un-served and that as a central library you could do certain things under the grant if you were working with other libraries; so the other libraries were Tinian and Rota. Now, the grant was very specific, just for public libraries [academic libraries did not qualify]. So when writing the grant, those monies would support only the public libraries functions. [But since the collegiate and public libraries were housed together on the outer islands] we could do quite a bit of things such as supply about five hundred dollars worth of periodical subscriptions and newspapers. And we paid for the telephone in the Tinian Library. Now anything done for the Public Library could be used ...in what some might call a schizophrenic function as being a college and a public library (Educator D).

For its part, the NMC contributed ten thousand dollars in cash toward the grant that provided the Public Library with a sizeable collection of books. This allocation helped the Public Library meet a major part of the federal grant requirements.

To accomplish all of this structurally (and legally), a consortium had to be formed. The Commonwealth Librarian, in his interview, described the formation of the consortium as follows:

I wrote a thorough document...it was a two-part thing where the Public Library will do certain things for the College Library and the College Library will do certain things for the Public Library with various differences here and there. This was drafted and went around to the President and Vice President and others and they [NMC administrators] wanted to have their legal counsel review it which was done. There were a few minor changes made to it but essentially the College President signed it, the College Librarian signed it, the Chairperson of the Commonwealth Library Council, which is the governing body for the Public Library signed it, and the Public Library Director signed it and then for good measure the College Legal Advisor also signed it. So we had a document then and the last signature was on May $7^{\text {th }}, 1999$, if I remember it correctly (Educator D).

The consortium agreement produced a number of positive outcomes. First, it allowed the public library to both get the cash it needed to meet the grant requirement and 
also make the case that it was serving underserved areas (i.e. the combined outer island libraries). It also produced economies of scale because private vendors now began viewing the public and collegiate libraries as one entity and could justify selling goods and services at a lower rate. One example is the Dynix system-a computer based modular system for library science that was compatible with Microsoft Windows technology and could therefore be networked. The NMC Library had been the pioneer at the college for computer technology, however, as time passed, the almost monthly upgrades of computer systems eventually made this older, DOS (direct operating system) based technology out-moded and inadequate. Because of the economy of scale created by the establishment of the consortium, the college could upgrade what had become an outmoded system.

To illustrate the huge economy of scale realized by this one aspect of the consortium formation, one Saipan respondent stated:

If the college were to go in this alone [purchasing the Dynix system] we would have had to expend ninety thousand to over one hundred thousand dollars. As a result of the consortium, our final outlay was eighteen thousand dollars. You cannot go wrong when you get into this kind of collaborative effort. It is a winwin situation for all the agencies involved; for all the consortium members involved, and it will ultimately open doors for more [governmental] partnerships in the future (Educator B).

Thus, establishing a consortium was the structural mechanism that was used on Saipan to promote library resource sharing. Operationally this meant that, on Saipan, unlike on the outer islands, the public and collegiate libraries remained separate physically and books purchased by one of the libraries which were housed in the other library were technically simply on loan. For all intents and purposes-most notably 
purchasing and the elimination of duplicate purchases - the two libraries functioned as a combined entity.

Why Form a Consortium Rather than Consolidate?

One benefit of the consortium arrangement over outright consolidation was the consortium arrangement did not require the approval of the political system that on Saipan was complex with diffuse power centers and not in the control of an all-powerful Mayor. Another benefit was it allowed the two autonomous governing boards-one for the Public Library and the other for the College system - to officially retain their powers and independent statuses. This was important because it is unlikely that members of either board would have agreed to relinquish their status and the perceptions of power that membership on either board conveyed.

The consortium idea could be seen as a kind of end-run maneuver around government policymakers. The benefits of the consortium have been so great and the costs in terms of disruption of the system so low, however, that, to date, none of the official policymakers has objected to the arrangement. Since the illusion of separateness has been maintained, it is unlikely that anyone will object to the arrangement in the foreseeable future. The consortium arrangement is a prime example of both a win-win solution to a series of problems and the importance of backdoor solutions that do not disrupt the symbols (and, sometimes, the illusions) of power within public life.

Conclusion: Postscripts to the Consolidation/Consortium Storylines During the period of time between the consolidation of the public and collegiate libraries on the two outer islands and the beginning of library resource sharing through the establishment of a consortium on the main island of Saipan, on the one hand, and the 
writing of this dissertation, on the other, the total resource sharing project has made quantum leaps forward. On Rota, the first phase of the building of a new NMC-Rota campus has been completed and the Vocational Education area was in operation in fall semester of 2002. The new campus includes a brand new combined Public/NMC Rota Library that is scheduled to open for students and the public to use in time for spring semester 2004.

Furthermore, the public and collegiate library relationship is not just a matter of shared facilities. A positive and ongoing relationship has begun to spill over into all areas of the political/collegiate relationship. This is what one Rota politician said after being asked about the about the current relationships between the college and the Public Library:

We have a very good working relationship with the college, especially now with the new College Administrator. She seems to be a very aggressive lady and she has a lot of vision to improve the college. And her willingness to work with my office...I am very accommodating to her needs because I am formulating a Rota plan as for CIP with the support of the Rota Legislative Delegation and the Municipal Council (Politician C).

On Tinian, there is planning going on for the combined Public/NMC Tinian Library facility. This will house the consolidated library with a museum in a new building. Construction should begin sometime in late 2004. The structure is slated to be located on the campus of NMC Tinian. This building effort is linked with a much larger construction effort that is rooted in inter-organization cooperation and communication, the sort of cooperation and communication that was required to consolidate the two libraries years before and which the combined libraries now symbolize. Here are the words of one Tinian politician who was interviewed as part of this study: 
The vision we [the political leaders] have for the NMC-Tinian campus is to one day specialize in a certain field of studies. So building the facilities now and slowly moving towards that goal is being accomplished as we speak. For us [NMC] to complete the master plan of the college is to continue to go to these people [local political leaders], continue to sit down with them; continue to profess the importance of building the educational institution here on Tinian. A continued dialog with community leaders is very important. I think my current success in building all these [facilities] up to this point is that continued communication; that continued presence... always there on the doorstep. Every time they open the office, you say, we need these things for education. Sooner or later, you are going to get the things that you're looking for (Politician A).

On Saipan, the new Dynix computer program system, was purchased because of the economies of scale that were created when the public/collegiate library consortium was established, has been installed at both the Public Library and at NMC Saipan Library. This system was functional by the start of fall semester 2002. This is what one respondent said of this product of the consortium agreement:

When the new Dynix system is in place, anybody in the Commonwealth that could get access to a computer [with Internet capability], be it at their home, office, wherever, eventually would be able to tap in at either one of the libraries [on Saipan]. Before, it would have entailed a lengthy trip or a phone call to find out what is available at the libraries. The M.O.U. and the agreement also have provisions that other institutions can join [the total resource sharing project] ...perhaps the Public School System or maybe the Law Library, or the CHC [Commonwealth Heath Center] Library might be interested (Educator D).

Finally, one respondent commented on how the cooperative activities occurring in the NMC-activities that, in many cases, can be traced back to or, at the very least, can be symbolized by the various forms of library resource sharing that developed on Saipan and on the two outer islands-were beginning to influence other places in the Pacific:

I am not saying that we [NMC] are always the models [sic], in testing out the rough waters, so to speak, in this kind of venture but I really do expect that out of this it could benefit other regional areas. I know that that's what we've been doing and for your information with the Pacific Post Secondary Education Council (PPEC), which are [sic] a group of [college] Presidents and one of the 
things that we do in this group is that we share information of what works and what doesn't work. The magnitude of the success of such a [library] consortium will not only remain here in the Commonwealth; the model that we have established can be extended to other areas in the Pacific (Educator B).

One positive result from the mass construction on the outer islands has been the pressure placed upon the C.N.M.I. Legislature to assist NMC Saipan. When I asked one of my Saipan respondents about this situation, her response was:

I was talking with some of the legislators the other day, and they were embarrassed to see that Rota and Tinian are putting substantial amounts of money into their capital improvement to build not only new libraries but entire new college campuses while absolutely no CIP funding has been awarded to NMCSaipan since its beginning in 1981 (Educator A). 


\section{CHAPTER FIVE}

\section{DISCUSSION}

This chapter begins with a brief review of key research findings. This review is organized around the study's three research questions. The focus shifts to a discussion of the implications of the findings for policy and practice. Finally, the chapter concludes with a discussion of implications for further research.

A Review of Key Findings Organized Around the Three Research Questions:

The Importance of Context in Understanding

Leadership Challenges, Strategies, and Styles

When this dissertation was conceptualized and the research questions articulated, I anticipated that the data would reveal a wide range of leadership challenges and responses to those challenges. The research questions that were articulated reflected this expectation. As the dissertation work unfolded, however, it became apparent that discrete leadership challenges and strategies were considerably less important than the overall need for those promoting the resource sharing idea to understand contextual factors and to use this understanding in promoting the resource sharing idea. Thus, most of what will be written below will focus on the cultural, economic, and political characteristics of the C.N.M.I. that were discussed in detail at the outset of Chapter 4. Question \# 1: What Were the Major Challenges Encountered in Achieving Total Resource Sharing Among the Public and Collegiate Libraries in the Commonwealth of the Northern Mariana Islands?

The major challenge was to understand and accommodate the culture and the political environment and to exploit change opportunities that resulted from economic 
factors. All three of these elements turned out to be far more important in understanding what happened in the library consolidation/cooperation program than the knowledge of specific leadership challenges and the responses to these challenges. Indeed, most of the leadership challenges that can be identified in the stories recounted in Chapter 4 , must be seen as being subsumed by one overarching challenge and strategy: to act in contextually appropriate ways.

The challenge of exploiting an economic crisis. The economic context described at the outset of this chapter made the consolidation/cooperation idea not only appealing, but a virtual necessity as time went on. In the years after the suggestion to engage in consolidation/cooperation, the logic of the strategy became apparent to virtually all of the stakeholders. One reason for this, of course, was that everyone gained something through consolidation/cooperation and, especially on the outer islands, there was really nothing to lose.

For instance, the satellite campuses on the outer islands quite literally had no funds to purchase books or materials and no space to put any books or materials that might have been purchased. When the promise of funding from the Saipan campus was used as an incentive for sharing library resources, something was gained and nothing was lost on the satellite campuses. These funds were used to "barter" for space in the public libraries which had plenty of space, but, prior to consolidation/cooperation, very little funding to purchase books and other materials to fill the space. On the outer islands the economic context was such that, in part, consolidation/cooperation was a win-win decision. This quickly became apparent, especially to college administrators who wanted 
to build accredited academic programs. Accreditation agencies, of course, expect to see libraries that support the academic programs.

The situation was a bit more complex on the main island of Saipan. Here, for instance, more had to be done to set the stage for the shared resources initiative to be successful. A number of things happened before the issue even appeared on politicians' radar screens. Specifically, certain relationships had to be established between key stakeholders at the college and the C.N.M.I. Public Library. The President of the College had to support the initiative to insure subordinates would follow suit and to insure funding was approved for the endeavor. The Commonwealth Librarian also had to support the initiative for similar reasons. In addition, a third party had to be involved as the liaison between the college and the Public Library and also as the liaison between the college on Saipan and the satellite campuses on Rota and Tinian. Additionally, this third person had to cultivate a strong, positive relationship with the Commonwealth Librarian to insure all stakeholders were on the "same page" during every step from conceptualization to implementation. In fact, by the time politicians on Saipan became aware of the library resource sharing option, a fair amount of resource sharing was already happening. What is important to understand is that, even in the more politically complex context of Saipan, it was the economic crisis that virtually forced everyone to accept the library resource sharing idea. On Saipan, this crisis was prompted by a number of factors including the fact that the C.N.M.I. historically was under-funded, the decision to build satellite campuses without providing adequate funding to an historically under-funded institution, the decline in tourism brought on by the collapse of a number of Asian economies, and tourists' fear of traveling due to the Gulf War of 1991. 
The challenge of understanding the cultural context. Leaders' understanding the cultural context also contributed significantly to their success in the library resources sharing initiative. For instance, on the outer islands, the hierarchical nature of Chamorro culture made resistance unthinkable once the all-powerful Mayors decided to support library resource sharing. Even in the more politically complex environment of Saipan, where multiple hierarchical structures existed and, consequently, more political actors had to be brought on board, the hierarchical nature of Chamorro culture made the politics of the implementation process manageable. For instance, neither the President of the College nor the Commonwealth Librarian had to worry about resistance from subordinates in their organizations. Furthermore, once the politicians saw the economicbased logic of endorsing the library resource sharing idea, it was even less likely that opposition to the idea would develop.

The fact that the idea of resource sharing was kept very low-key until the project was already in operation was a conscious one by the major stakeholders. Those who promoted the idea and "led" the initiative during the early years were aware of cultural norms about keeping information secret, and they acted in accordance with this norm. They realized that the idea could not ultimately be identified as theirs if it was to have any chance of implementation.

The norm of "saving face" is a critical element in the explanation of the success of the resource sharing project, since, once the initiative was in operation, it would be a great loss of respect and stature to those politicians who had supported the concept if anyone resisted the initiative and the initiative was undermined and failed. Politicians, in other words, wanted the program to be successful and this, coupled with the hierarchical 
nature of the culture, helped insure support for the resource sharing initiative and minimized opposition. Anything less than continued success of the resource sharing initiative meant that those at the top of the hierarchy would "lose face". The reader will recall that in Chapter 4, the norm of "saving face" was one of four norms enumerated under the cultural context of the C.N.M.I.

The importance of understanding and adapting to the political context. The political context turned out to be among the most interesting, and at least on the outer islands, the most important aspect influencing the success of the library resource sharing project. The Mayors of the outer islands of Rota and Tinian retain nearly dictatorial powers on their respective islands, so in these two instances the Mayors' support alone enabled the project to succeed. The Rota and Tinian contexts, in other words, are two cases where the Great Man Theory of leadership (Rost, 1993) is correct. The public at large, on the outer islands, either supported the mayors out of love, duty, and/or fear. Regardless of the reasons, a hierarchically and position-driven form of leadership was very much in evidence in both of the outer island situations.

Thus, the major leadership challenge on display in the political context of Rota and Tinian was garnering the support of these two influential individuals. As suggested above, the economic context was helpful. Those who were promoting the library resource sharing idea understood Chamorro cultural norms and very consciously attempted not to appear to be the authors of the idea, since the appearance that an idea that was being proposed came from outsiders would generate opposition even to the most compelling idea. It is significant that most of the people interviewed about the 
implementation process indicated that they had helped developed the idea of library resource sharing and were instrumental in implementing it.

As noted in the discussion of the economic context, the situation on the main island of Saipan, where the seat of the C.N.M.I. government resides, was a bit more complex. In actuality, on Saipan there is a Mayor, however, the Mayor has very limited political power and responsibility. Even the Governor of the C.N.M.I. does not possess the political clout on Saipan (or anywhere in the C.N.M.I.) that the mayors of the outer islands enjoy on their home islands. Because power is more diffuse on Saipan, the political component of the library resource sharing initiative on Saipan was more complicated. Thus, one can discern a number of leadership challenges and strategies in the Saipan context.

The Dean of Learning Resources at NMC made a concerted effort to develop a smooth working relationship with the Commonwealth Librarian in an effort to ease budget requirements and still mutually benefit the public and college libraries. For example, they agreed to alternate the purchase of large ticket items such as the Thomas Register, current editions of Encyclopedia Britannica, etc. Cooperation efforts such as this were spun into stories that were recounted to Board members; Board members, in turn, told the stories to politicians; and the politicians, in time, "came up with the idea" of total resource sharing among college and public libraries as a way to do more with less in difficult economic times. Anyone who had initially helped develop the idea of library resource sharing knew better than to claim authorship. Such a claim would not have been culturally appropriate and, hence, unwise politically. 
Question \# 2: How Were the Leadership Challenges Addressed; Were They Solved, and, if so, How Were They Solved?

The major leadership challenge in promoting and implementing total resource sharing among college and public libraries in the C.N.M.I. was to execute all actions in culturally appropriate ways. With such a small indigenous population there is obviously a massive network of relatives in both elected and appointed government positions. Indeed, it is nearly impossible to separate the political and cultural contexts because they overlap extensively. Therefore, a cultural aspect, such as male dominance, is also a political aspect because women, in general, are not looked upon as leaders. Therefore, it follows that they are incapable of conceptualizing and implementing an initiative as the library resource sharing project. In essence, even though the first President of the College (a female) was the true visionary of this idea, she was never-and could never-be given credit for it because she is a woman. Because she is Chamorro, however, she was knowledgeable about Chamorro culture and, therefore, she laid the project foundation orally (due to the strong oral tradition in these islands), and kept early implementation efforts low-key (the norm of secrecy of information). Once the program was in-place and successful, she allowed others to take the credit allowing several male politicians to "save face".

In addition to the cultural ramifications, adjusting one's strategies to the particular political context in which one is working was critical. This meant that very different strategies were employed on Saipan and on the outer islands. Consolidating collegiate and public libraries was a viable option on the two outer islands, in large part, because only one political actor had to be convinced of the wisdom of this approach for it to 
happen. That person, of course, was the Mayor. Those who led the resource sharing initiatives understood that outright consolidation would be almost impossible to get implemented on Saipan where many political actors with many different self interests would have had to agree to any consolidation proposal. Therefore, on Saipan, those who led the process embraced the formation of a consortium as the strategy with which to implement resource sharing.

Finally, the economic aspect was the factor that ultimately tipped the scales in favor of the library resource sharing project. The dire economic situation helped make the idea of total resource sharing very appealing. Those who led the initiative recognized the importance of these economic factors and used a number of economic crises to promote their resource sharing agenda.

Question \# 3: What type(s) of leadership emerged in response to these challenges?

In the final analysis, the findings have shown that the political stream, the economic stream, and the cultural stream were flowing together at precisely the correct time for this bold and innovative project to meet with success. This insight suggests that questions about types or styles of leadership may miss the point. What was needed by those who led this initiative was (1) an understanding of what was culturally appropriate and inappropriate and a willingness to embrace particular strategies and ways of doing business that reflected cultural norms and avoid behaviors and ways of doing business that violated culturally sanctioned norms and practices; (2) an understanding of the political context and a willingness and an ability to redefine strategies in ways that could be "sold' within a particular political environment (this meant abandoning the consolidation approach that had worked so well on both of the outer islands and 
embracing, instead, the consortium strategy); and (3) a willingness and ability to exploit economic crises.

In summary, the findings show that although leadership styles are important to recognize, it is more important to understand the cultural environment and execute one's actions (leadership style) in culturally appropriate ways. This underscores that leadership styles are (or should be) situationally driven.

Implications for Policy and Practice

Due to the sizeable economies of scale realized in this cooperative effort, it is readily apparent that similar cooperation/consolidation efforts would be applicable-particularly among and between other governmental agencies. Such C.N.M.I. agencies as Coastal Resource Management, Division of Environmental Quality, and Lands and Natural Resources have many overlapping responsibilities. Duplication of efforts could be eliminated and economies of scale could be realized by a cooperative effort. Although this type of cooperation seems logical on paper, it must be remembered that the political context and personal "kingdoms" would be more difficult challenges to overcome because each agency would have to give up some area(s) of jurisdiction. Even if other areas of responsibility were "bartered" in return, it is doubtful if those administering each agency would see this exchange as a gain as opposed to a loss.

To move outside of the C.N.M.I., the Palau Community College Library (in the Republic of Palau) and the Palau Public Library have already instituted a similar program of cooperation/consolidation of college and public library total library resource sharing based on the model conceived in the C.N.M.I. This proves that the concept is viable in 
other areas of Micronesia where cultural, political, and economic norms are similar to those of the C.N.M.I.

In another area of Micronesia, on the islands of Chuuk (formerly called Truk) the cultural, economic, and political contexts are more crucial and more varied than in the C.N.M.I. For example, the islands of Chuuk are the most poverty stricken in Micronesia. Having always been in poverty, the economics of scale mean less than in an economy that has been quite robust since the late 1980s (the C.N.M.I.). In addition, although Chuuk has a variation of the United States style of central government, the various agencies rarely function as their counter parts in the United States. Additionally, appointments to the United States equivalent of cabinet secretaries are based on familial relationships and/or campaign support for the Governor of Chuuk. Merit or experience are generally not taken into account. In the cultural context of Chuuk books are held in low esteem because Chuukese culture is much more into the oral tradition than the written word. Therefore, the economic context, the political context, and the cultural context are somewhat dissimilar to those in the C.N.M.I. This dissimilarity is especially true in the economic context.

An additional area of Micronesia that is quite distinct from the C.N.M.I. is the island state of Yap. Yap is considered by most people familiar with Micronesia to be the most traditional of all the Micronesian island nations. As for the political context, like Chuuk, Yap has a central government similar to that of the United States, however, the traditional chiefs of the various districts, islands, etc. hold the real power. As the chiefs say, so it is done on Yap. Although this is similar to the power of the Mayors of the outer islands in the C.N.M.I., the analogy breaks down because only the main island of Yap has 
any real library resources. There is only one "have" but many "have nots". The economic context in Yap is more similar to that of Chuuk than to that of the C.N.M.I. Yap has very few visitors and no industry of any consequence. This has always been the economic reality of Yap, so economy of scale means little, especially in respect to libraries, when the critical priority of most Yapese is to simply have enough to eat. Last of all is the cultural lack of respect for the value of books. Yap is the strongest proponent of the oral tradition in all of Micronesia. What good are books when, "the wisdom is in the basket?" This Yapese phrase refers to the small woven pouch that the adult males of Yap carry and which holds beetlenut, a narcotic type nut that is chewed and decisions made under its influence. As the reader can see, the three contexts are extremely more complex in Yap than in the C.N.M.I.

To move beyond Micronesia into the South Pacific (i.e. American Samoa) the cultural, political, and economic contexts flow much more akin to those of the C.N.M.I. American Samoa has long had U.S. influences in politics, economy, and education so the political context is similar to the C.N.M.I. However, the traditional chiefs still retain much power. The economic context in American Samoa is similar to the conditions of the present C.N.M.I. There are insufficient funds to maintain the governmental status quo, much less funds available for expansion and new programs. Contrasted to American Samoa is Western Samoa, an independent country, where the U.S. influence has had less impact, especially on the cultural and political contexts. The traditional ways are more pronounced on Western Samoa than on American Samoa therefore, implementation may be less of a problem. However, if books are of little value there and/or libraries do not 
exist, then the value of this concept of total resource sharing among libraries may be of minimal value.

As for the state of Hawaii, I suspect that implementation of such a library resource sharing plan would be nearly impossible to implement successfully. This reasoning is based on two factors. Since Hawaii is one of the 50 States, its form of government relies on creating a winning coalition in a political situation or a proposal is doomed. As Hammer and Champy (1993) noted, building a winning coalition in a complex governance system, like the system in Hawaii, is exceedingly difficult. Second, the time involved having such a proposal as academic and public library total resource sharing passed and implemented in Hawaii is prohibitive. For example, while attending a summer session at University of Hawaii, there was an obvious need for an additional course in the degree program I was enrolled in. When I asked about the viability of creating such a course, I was told that the total time to conceive, create, and implement a new course typically takes two years. Often, the person initiating the request has departed from the University of Hawaii prior to a decision being made whether or not to add the course (J. Haak, personal communication, June 2001).

Implications for Further Research

Because the contextual factors of culture, politics, and economics were so important in the C.N.M.I., it is imperative that scholars study other attempts at resource sharing in very different contexts. We need to know, for example, whether culture matters as much elsewhere as it did in the C.N.M.I., and, if it does, how do different cultural norms shape the resource sharing initiative. It would be helpful to understand how others negotiate in other political environments (for example where traditional chiefs 
hold the power instead of an elected official) and how (and whether) the notion of resource sharing can be "sold" in contexts that are not experiencing the extreme economic problems that tend to characterize the NMC, and to a greater extent the C.N.M.I. as a whole.

As was mentioned in Implications for Policy and Practice above, the cultural, economic, and political contexts can be quite different than those in the C.N.M.I., even within other entities in Micronesia. The political structure may be extremely different as on Yap. The cultural context would be extremely important in a culture that does not value books and libraries but rather depends on the oral tradition and on other more traditional sources of wisdom. This context is quite common on the islands of Micronesia. The economic context may, or may not, be important because economy of scale means little if there is no economy to begin with or no overlap of governmental agencies exists.

There are obviously many areas outside of Micronesia and the Pacific as a whole. For further research to be of any value, researchers will need to identify an agency or agencies where duplication of efforts/responsibilities exists. First, there has to be a need before a study takes place. Second, the researcher(s) need to study the economic, cultural, and political contexts of the proposed areas/agencies to be involved in a consolidation/cooperation effort. Perhaps other contexts may well be important also, for example, geographic location and national political alliances. Finally, educational and governmental institutions need to be extremely cautious before endorsing any research and/or "buying in" to purported findings. The researcher(s) should be well acquainted with the people and the cultures (human and organizational) of the area(s) to be studied. 
A little knowledge is a dangerous thing and often well intentioned researchers can be led to faulty conclusions. Margaret Meade in Samoa and the United States Government in Vietnam are two prime examples.

\section{Conclusion}

This dissertation has looked at (ex post facto) the challenges of conceiving and implementing a library cooperation/consolidation model of total resource sharing for a particular geographic and political area. Standard qualitative research methods were employed for gathering data, coding the data for themes, and in narrative form, telling the story of the findings. The information presented has added to the small, but growing, literature base on libraries in Micronesia, and total resource sharing among libraries world-wide. The total resource sharing between collegiate and public libraries (with minor variations) has already been implemented in the Republic of Palau based on the data presented in this dissertation thus lending credence to the viability of incorporating the model elsewhere. Additional study in other cultures, political environments, and economic contexts would be extremely valuable. 


\section{REFERENCES}

Anderson, G. (1997). Re-engineering the academic library: New services through institutional alignment and leadership. Essen University Library, 21, 115-135.

Bach, H. (1957). Acquisition policy in the American academic library.

College and Research Libraries, 18, 449-461.

Baldwin, R. (1922). What should be the relation between the public, and the high school library? Supplement to Illinois Libraries, 4, (4), 180-181.

Ballard, T. H. (1990). The unfulfilled promise of resource sharing. American Libraries, 21, 990-993.

Bashein, B., \& Markus, M. L. (1994). Preconditions for bpr success: And how to prevent failures. Information Systems Management, 11, 7-13.

Bodker, A., \& Anzalone, V. (1964). Working together: Public, school and college libraries cooperate in Tangipahoa Parish. Bulletin of the Louisiana Library Association, 27, 175-176.

Bridges, W. (1991). Managing transitions: Making the most of change. Reading, MA: Addison-Wesley Publishing Company.

Brown, F., \& Mashinic, A. (1983). Resource sharing in community colleges: Community college library services combine in Houston public library branch. American Libraries, 22, 91-92.

Burke, W. W., \& Litwin, G. H. (1992). A causal model of organizational performance and change. Journal of Management, $18,523-545 .$.

Clyde, P. H. (1935). Japan's Pacific mandate. New York, NY: Macmillan Co.

Cunningham, L. (1992). Ancient Chamorro society. Honolulu, HI: Bess Press. 
De Gennaro, R. (1977). Copyright, resource sharing, and hard times: A view from the field. American Libraries, $8,326-328$.

Donmoyer, R. (1995). A knowledge base for educational administration: Notes from the field. In R. Donmoyer, M. Imber, \& J. Scheurich (Eds.) The Knowledge Base in Educational Administration: Multiple Perspectives (74-95). Albany, NY: The State University of New York Press.

Dougherty, R. (1997). Getting a grip on change. American Libraries, 28, 40-42.

Douglas, J. (1976) Investigative social research: Individual and team field research. Sage Library of Social Research, 29, Beverly Hills, CA: Sage Publications.

Duck, J.D. (1993). Managing change: The art of balancing. Harvard Business Review, 71, 109-119.

Eberhard, G. (1999). Plans for shared-use libraries in the works. American Libraries, 30, 21-22.

Esterquest, R. (1958). Aspects of library cooperation. College and Research Library News, 19, 200-208.

Gerould, J. T. (1907). Some suggestions toward cooperation between the school and the library. Minnesota Department of Education Library Notes and News, 2, 70-73.

Glesne, C. (1998). Becoming qualitative researchers: An introduction (2 ${ }^{\text {nd }} \mathrm{Ed}$.). New York, NY: Addison Wesley Longman.

Goetzfridt, N. (2000, November). "Life in the round" and the history of libraries in Micronesia. Symposium conducted at the meeting of Pacific Island Archivists' and Librarians' Association, U.S. Territory of Guam. 
Goleman, D. (2000). Leadership that gets results. Harvard Business Review, 78, 78-

Hacken, R., (1992). The rlg Conoco study and its aftermath: Is resource sharing in limbo? Journal of Academic Librarianship, 18, 17-23.

Hammer, M., \& Champy, J. (1993). Reengineering the corporation. New York, NY: Harper-Collins.

Hanlon, D. (1994). Pre-colonial times. In Howe, K.R., Kiste, R., \& Lal, B. (Eds.), Tides of change. Honolulu, HI: University of Hawaii Press.

Healey, J. (1971). Public-academic library cooperation. College and Research Library News, 32, 121-126.

Hezel, F. X., \& Berg, S. J. (Eds.) (1979). Micronesia: Winds of change. Honolulu, HI: Trust Territory of the Pacific Islands: Omnibus Program for Social Studies.

Higginbotham, B., \& Bowdoin, S. (1993). Access versus assets. Chicago, IL: American Library Association.

Howe, K. R., (1984). Where the waves fall: A new South Seas Islands history from first settlement to colonial rule. Sydney, Australia: Allen \& Unwin, Honolulu, HI: University of Hawaii Press.

Howe, K. R., Kiste, R., \& Lal, B., (Eds.). (1994). Tides of change. Honolulu, HI: University of Hawaii Press.

Janesick, V. J. (1994). The dance of qualitative research design: Metaphor, methodology, and meaning. In N. K. Denzin, \& Y. S. Lincoln (Eds.) Handbook of qualitative research (pp. 209-219). Thousand Oaks, CA: Sage Publications. 
Kanter, R. M. The enduring skills of change leaders. (Su, 1999). Online Journal, Leader to Leader [On-line serial]. Available: Doc. No. 13 (10 p.). http://pfdf.org/leaderbooks/L2L/summer99/kanter.html

Kanter, R. M., Stein, B. A., \& Jick, T. D. (1992). The challenge of organizational culture: How companies experience it and leaders guide it. New York, NY: The Free Press.

Kotter, J. P., \& Heskett, J. L. (1992). Corporate culture and performance. New York, NY: The Free Press.

Kronick, D.A. (1982). Goodbye to farewells: Resource sharing and cost sharing. Journal of Academic Librarianship, 8, 132-136.

Ladner, S. J. (1992). Resource sharing by sci-tech and business librarians: Informal networking and the role of professional associations. Special Libraries, 83, 96-112.

Logsdon, R. \& Nelson, C. (1965). Cooperation: Pitfall or panacea. Special Libraries, 56, 571-575.

McHenry, D. (1975). Micronesia: Trust betrayed. New York, NY: Carnegie Endowment for International Peace.

McPherson, G. (1972). Small town teacher. Cambridge, MA: Harvard University Press. McPhetres, S. (1997). Self-government and citizenship in the Commonwealth of the Northern Mariana Islands U.S.A. Queensland, Australia: The Imprint Group. Medaris, L. (1984). Academic and public library cooperation: Warrensburg style. ShowMe Libraries, 36, 66-68.

Meyer, F., \& Hines, E. (1998). Resource sharing in community colleges. Community College Journal of Research and Practices, 22, 133-134. 
Morgan, E. L. (1998). Resource sharing and consortia, or, becoming a 600 pound gorilla. Computers in Libraries, 27, 240-242.

Moses, J., \& Kennedy, P., (Eds.). (1977). Germany in the Pacific and the Far East. St. Lucia, Queensland: University of Queensland Press.

North Dakota Advisory Council on Libraries. (1991). A discrete inquiry: Is the merging of school and public libraries a viable option in the state of North Dakota? North Dakota Advisory Council on Libraries Evaluation and Feasibility Report. Bismarck, ND.

Osborne, D., \& Gaebler, T. (1992). Reinventing government: How the entrepreneurial spirit is transforming the public sector. Reading, MA: Addison-Wesley Publishing.

Patton, M. Q. (1990). Qualitative evaluation and research methods. Newbury Park, CA: Sage Publications.

Payne, L. (1998). Reinventing the public library for the $21^{\text {st }}$ century. Libraries Unlimited, 231-235.

Peattie, M. (1988). Nanyo: The rise and fall of the Japanese in Micronesia, 1885-1945. Honolulu, HI: University of Hawaii Press.

Piternick, G. (1963). Library growth and academic quality. College and Research Libraries, 24, 223-229.

Polkinghorne, D. (1995). Narrative configuration in qualitative studies in education. Qualitative Studies in Education, 8, 5-23.

Quinn, V. (1945). Geography of the Pacific. New York, NY: J.B. Lippincott. Ravelo, J. (2003, April 26). Jury finds Atalig guilty. Saipan Tribune, pp. 1, 4. 
Reid, C. (1965). The school-public library crisis. The American School Board Journal, 150, 13-14.

Rost, J. C. (1993). Leadership for the twenty-first century. Westport, CT: Praeger. Russell, S. (1983). Rising sun over the Northern Marianas: Life and culture under the Japanese administration (1914-1944). Saipan, C.N.M.I.: Department of Education in conjunction with The National Endowment for the Arts.

Rutstein, J. S. (1985). National and local resource sharing: Issues in cooperation collection development. Collection Management, 7, 1-10.

Saunders, C. M. (1999). The human element in the virtual library. Library Trends, 147, 771-787.

Schneider, B. (Ed). (1990). Organizational climate and culture. San Francisco, CA: Jossey-Bass Publishers.

Schwanz, K. (2000). Thinking about a joint-use library? College and Research Library News, $61,478-480$.

Schwartz, C. A. (1997). Restructuring academic libraries: Organizational development in the wake of technological change. Association of College and Research Libraries, 61, 478-480.

Sewell, P. (1970). Development of library services. Journal of Librarianship, 2, 32-42.

Shields, J. (1999). Transforming organizations. Information, Knowledge, and Systems Management, 1, 105-115.

Siddiqui, M. A. (1989). A comparative study of interlibrary loan functions and the development of a model interlibrary loan network among academic libraries in Saudi Arabia. Johannesburg, South Africa: University of Natal Press. 
Stake, R. E. (1988). Case study methods in educational research: Seeking water. In R.M. Jaeger (Ed.), Complementary Methods for Research Education, 253-300.

Washington, DC: American Educational Research Association.

Swadling, P. (1986). Papua New Guinea's prehistory: An introduction. Borneo, Papua New Guinea: National Museum and Art Gallery.

In Howe, K.R., Kiste, R., and Lal, B. (Eds.) Tides of change. Honolulu, HI: University of Hawaii Press.

Swank, R. (1959). Too much and too little: Observations on the current status of university library resources. Library Resources and Technical Services, 24, 28-29.

Sweeney, R. (1994). Leadership in the post-hierarchical library. Library Trends, 43, 6294.

Trust Territory of the Pacific Islands Archives. (1947). Northern Marianas College, Saipan: C.N.M.I.

United States Census. (1990).

United States Census. (1995 mid-term update).

Welsch, E. K., (1983). Resources: The year's work in review. Library Resources and Technology Services, 27, 315-329.

Wiens, H. (1967). Pacific island bastions of the United States. Princeton, NJ: Van Nostrand Company.

Wolcott, H.F. (1994). Transforming qualitative data. Thousand Oaks, CA: Sage Publications.

Yennie-Donmoyer, J. \& Donmoyer, R. (1993). Creating a culture of writers with at-risk students. In R. Donmoyer, \& R. Kos (Eds.) At-Risk Students: Portraits, Policies, 
Programs, and Practices (pp. 343-367). Albany, NY: State University of New York Press.

Yin, R. (1984). Case study research: Design and methods. Beveriy Hills, CA: Sage Publications. 
APPENDIX A

MAPS OF THE PACIFIC ISLANDS

AND

THE COMMONWEALTH OF THE NORTHERN MARIANA ISLANDS 
wn

16

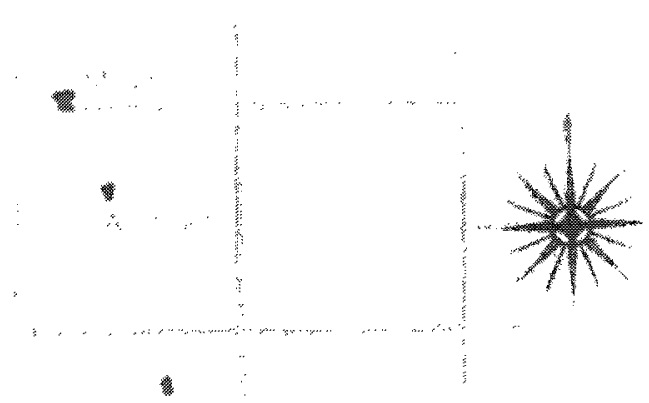

$\frac{9}{3}$

renk

161

等

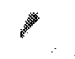

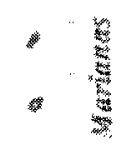

$47 N$

$$
\text { Q Q anks }
$$

Whing

- Forethe

os

$\frac{\sqrt{w}}{6}$

$$
\begin{aligned}
& \text { Pathmoer } \\
& \text { hed }
\end{aligned}
$$$$
\text { sut }
$$

a

$16 \mathrm{~N}$

Arakcats:

pret

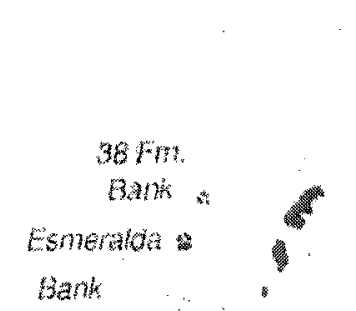

数

16

bank

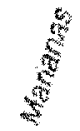

$\frac{35}{8 x}$

$4 n$

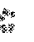<smiles>C=CC</smiles>

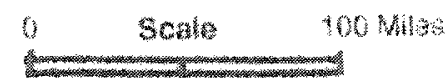

$13 \mathrm{~N}$

Tomblory of wath<smiles>c1ccccc1</smiles>

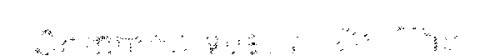

$\frac{1}{4}$

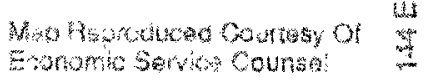

$\underset{3}{3}$

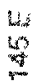

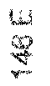

$\underset{n}{m}$ 
APPENDIX B

TIME LINES FOR THE CONSOLIDATION PROCESS ON

ROTA

TINIAN

AND THE COOPERATION PROCESS ON SAIPAN 
Time Line for Library Consolidation on the Island of Rota

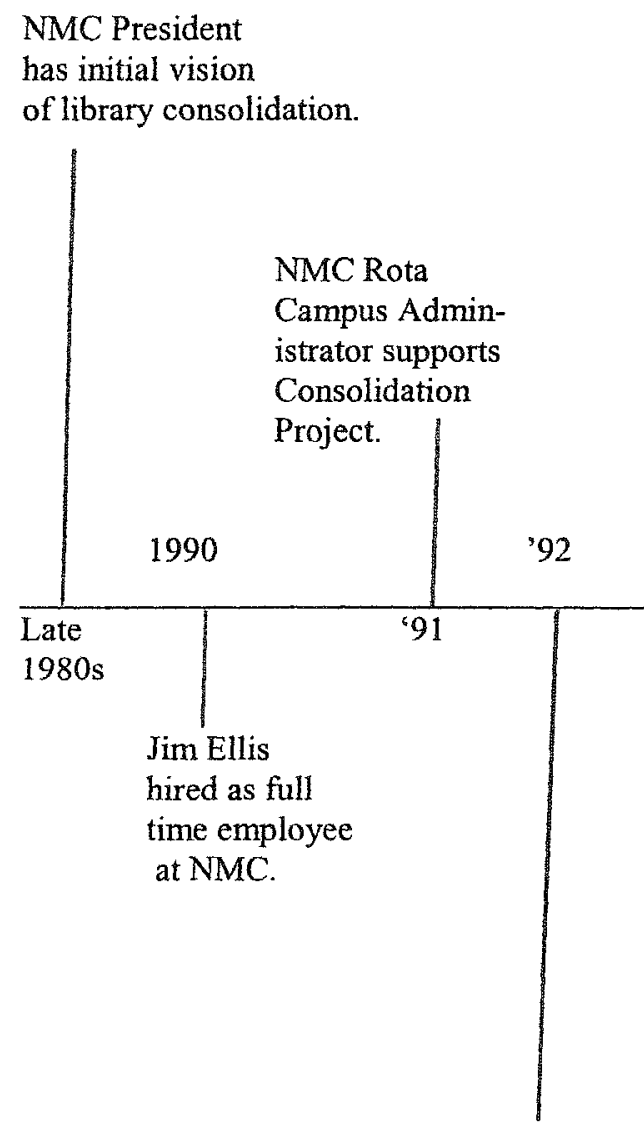

Jim Ellis promoted to

Assoc. Dir. of Library Services.

President assigns him to work on

implementation of Library

Consolidation Project.
NMC Rota

Campus Admin-

istrator \& Dean of

L.R. work out support

issue to NMC Rota.
CNMI Librarian \&

Dean of L.R. begin

"unofficial" consolidation

of NMC Rota and Public

Library on Rota.
Dean of L.R. \&

CNMI Librarian

budget for equip. materials, etc. for new facility.
Jim Ellis promoted
to Dean of L.R. He

begins massive support

to NMC Rota library.

Jim Ellis

promoted to Dir.

of Library Services.

NMC President

sends him to Rota

to negotiate MOU

for consolidation.

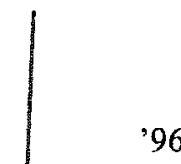

FEMA funding arrives. Dir. of

Library Services at NMC

He writes the

consortium proposal.

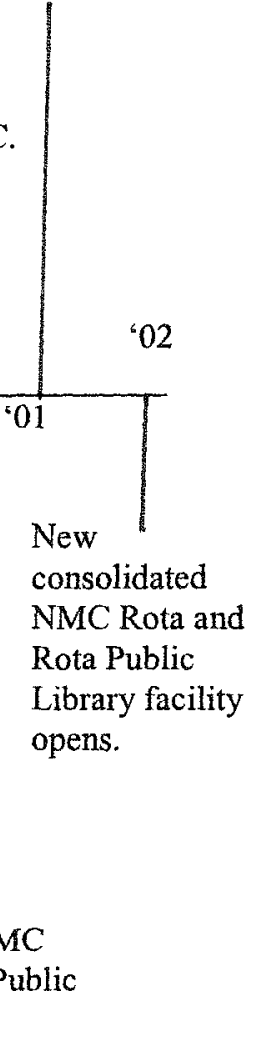

New CNMI

Librarian hired.

Strong working

relationship and

trust established

with Dean of L.R. at NMC. 
Time Line for Library Consolidation on the Island of Tinian

NMC President has

initial vision of NMC

Library and Public

Library

consolidation.

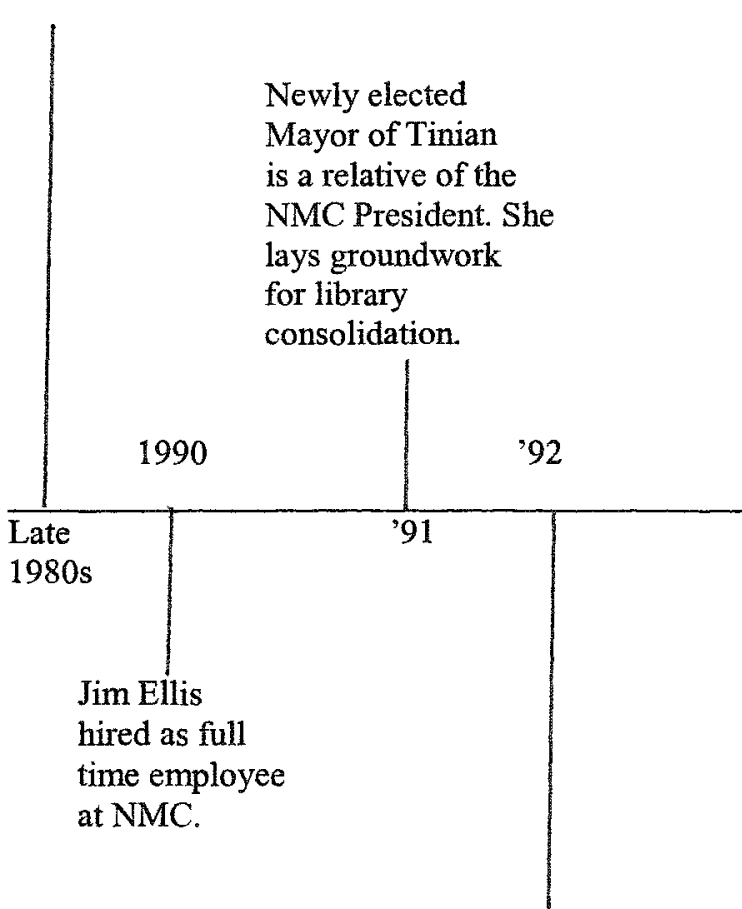

NMC President denies

certain courses to NMC

Tinian due to insufficient

library resources.
Initial agreements for

MOU are lined out.

NMC Tinian and Public

Schools create joint use

Resource Center.

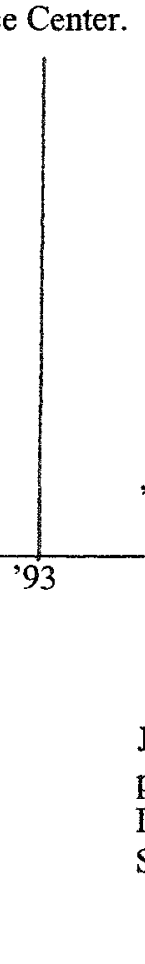

'94

195

Jim Ellis

promoted to

Director of Lib.

Services.

New CNMI Dir. of Library

Services hired. Strong

working relationship and

trust established with

the Dean of L.R. at NMC

'96

promoted to

L.R

to NMC Tinia

ibrary.

96

Dean of Learning Res.

and CNMI Librarian begin

"unofficial" consolidation of

NMC Tinian and Tinian

Public Library.

Library.
$\begin{aligned} & \text { Continued } \\ & \text { consolidation } \\ & \text { of NMC Tinian } \\ & \text { Library and } \\ & \text { Tinian Public } \\ & \text { Library. }\end{aligned} \mid$
'98
'97'
New Mayor elected.
Tinian Campus
Administrator to be
his Chief of Staff.
CNMI Librarian
hired by NMC
as Dir. of Library
Services for the
College.

Measure passed

on Tinian to use

CIP funds for construction

of new consolidated
Library and Museum. 
Time Line for NMC Library and Public Library Cooperation on the Island of Saipan

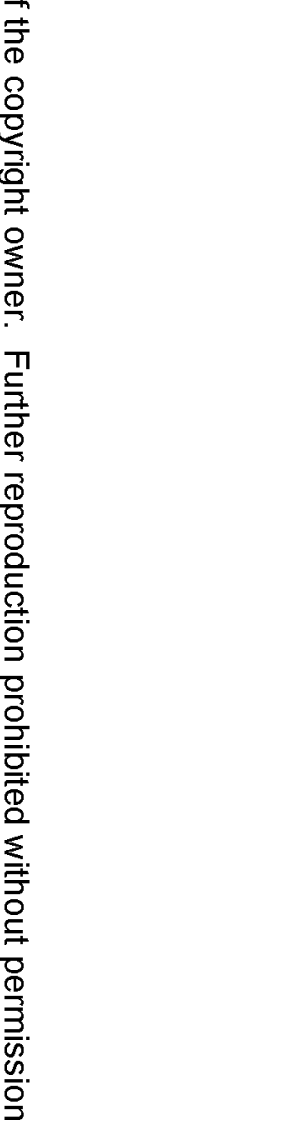

NMC President has

initial vision for NMC

Library and Public

Library consolidation

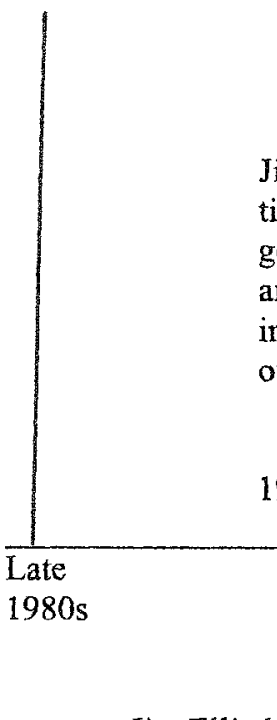

Jim Ellis hired as full time employee at $\mathrm{NMC}$.

990
Jim Ellis spends most of his time working with

NMC Campus Administrators

on Rota and Tinian to assist

them in development of the

planned consolidation project.

im Ellis spends

me learning back-

gournd of Public Lib.

and NMC Lib. He is

introduced to the Mayors

of Rota and Tinian.

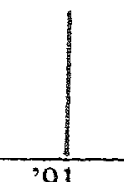

'92

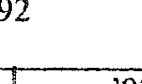

93

'94

1

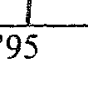

Jim Ellis continues close working relationship with Rota and Tinian.
Jim Ellis promoted to Assoc.

Director of Library Services.

Assigned by NMC President to work on implementation of Library Consolidation Project. He initiates close working relationship with NMC Campus Administrators on Rota and Tinian.
CNMI Librarian and Dean of L.R. begin "unofficial" cooperation by alternating years of purchasing high ticket library materials. They also exchange certain items

between various libraries using a hand receipt system.
On-going negotiations with software vendors.

New computer wiring installed at NMC Library. Training on new software takes place in Australia. 
APPENDIX C

SAMPLE CONSENT FORM

Reproduced with permission of the copyright owner. Further reproduction prohibited without permission. 


\section{INDIVIDUAL CONSENT FORM}

\section{University of San Diego \\ CONSENT TO PARTICIPATE IN RESEARCH STUDY}

You are being asked by Jim Ellis, a doctoral student in the School of Education at the University of San Diego, to participate in a research study on the total resource sharing among academic and public libraries in the Commonwealth of the Northern Mariana Islands. This is an agreement of the protection of your rights in this research study.

1. The purpose of this study is to document, ex post facto, the challenges and processes that that were encountered in planning, creating, and implementing a structure that would facilitate the total resources sharing (including facilities, personnel, budgets, equipment, and materials) among academic and public libraries in the C. N. M. I.

2. A narrative case study will be used. Methodology will include interviews, document review, and personal observations and recollections.. You will be given a list of open-ended interview questions in advance so you can think about your responses. I would like to set up a personal interview with you because other questions may arise during the interview that would have bearing on the project.

3. I will prepare an overall timeline from the interview data provided by all of the interviewees. You will have the opportunity to review and edit your interview material for accuracy, prior to it being included in the dissertation.

4. All information will remain confidential, in so far as possible, and every effort will be made to report findings in a non-identifying way. Participating individuals will not be identified by name. However, due to the fact there is only one institution of higher learning in the Commonwealth, and there are only two major populated islands in the Commonwealth (other than Saipan) there is the possibility that some readers may deduce the identity of one or more of the participants in the research.

5. Upon acceptance of the final dissertation by the doctoral committee, and once the manuscript has gone to the printer, all data gathered during the interview process will be destroyed. You will be given written notification once this destruction of the data has occurred.

6. Your participation is entirely voluntary, and you may withdraw from the study at any time without risk or penalty. 
7. There is no agreement, written or verbal, beyond that which is expressed on this consent form.

I, the undersigned, understand the above explanation and give consent to my voluntary participation in this research.

Signature of participant:

Date:

Print name and title:

Telephone: e-mail or fax: 
APPENDIX D

SAMPLE OF THE INTERVIEW QUESTIONS 


\section{INTERVIEW GUTDE TOPICS}

As Patton has described it, the interview guide approach is characterized as, "topics and issues to be covered are specified in advance, in outline form; interviewer decides sequence and working of questions in the course of the interview. (1990, p.288)." The strength of this approach is that "the outline increases the comprehensiveness of the data and makes data collection somewhat systematic for each respondent. Logical gaps in data can be anticipated and closed. Interviews remain fairly conversational and situational (p.288)." The following are the guide questions to be asked of participants in the interviews.

1. Would you draw for me a timeline of the combined library resource sharing project as you remember it on $<<$ name of the island $>>$ ? Please place major events that occurred at specific dates along the timeline.

2. Would you describe for me your role in the process of combining the Public and NMC Libraries here on $<<$ name of the island $>>$ ?

3. More specifically, even though the Public Library administration and the NMC administration desired to consolidate on $<<$ name of the island $>>$, could you explain the process for gaining political support for the consolidation to actually occur on $<<$ name of the island $>>$ ?

4. What role or roles did you (and do you now) play in the on-going process of the consolidation/cooperation here on $<<$ name of the island $>>$ ?

5. Could you tell me of anyone else on $<<$ name of the island $\gg>$ that may have been involved in the process of library consolidation, and what role or roles they played?

6. Can you describe for me any economies of scale that you have found in the consolidation of the libraries on $<<$ name of the island $>>$ ?

7. When did these economies of scale occur?

8. Can you think of any other information that might be relevant to the process of consolidation/cooperation between the academic and public libraries? 